\title{
Semaphorin signaling in vertebrate neural circuit assembly
}

\author{
Yutaka Yoshida* \\ Division of Developmental Biology, Cincinnati Children's Hospital Medical Center, Cincinnati, OH, USA
}

\section{Edited by:}

Robert W. Burgess, The Jackson

Laboratory, USA

\section{Reviewed by:}

Florentina Soto, Washington

University in St. Louis, USA

Peter Gerard Fuerst, University of

Idaho, USA

\section{*Correspondence}

Yutaka Yoshida, Division of

Developmental Biology, Cincinnati

Children's Hospital Medical Center.

3333 Burnet Avenue, Cincinnati, $\mathrm{OH}$ 45229-3026, USA.

e-mail:yutaka.yoshida@cchmc.org
Neural circuit formation requires the coordination of many complex developmental processes. First, neurons project axons over long distances to find their final targets and then establish appropriate connectivity essential for the formation of neuronal circuitry. Growth cones, the leading edges of axons, navigate by interacting with a variety of attractive and repulsive axon guidance cues along their trajectories and at final target regions. In addition to guidance of axons, neuronal polarization, neuronal migration, and dendrite development must be precisely regulated during development to establish proper neural circuitry. Semaphorins consist of a large protein family, which includes secreted and cell surface proteins, and they play important roles in many steps of neural circuit formation. The major semaphorin receptors are plexins and neuropilins, however other receptors and co-receptors also mediate signaling by semaphorins. Upon semaphorin binding to their receptors, downstream signaling molecules transduce this event within cells to mediate further events, including alteration of microtubule and actin cytoskeletal dynamics. Here, I review recent studies on semaphorin signaling in vertebrate neural circuit assembly, with the goal of highlighting how this diverse family of cues and receptors imparts exquisite specificity to neural complex connectivity.

\section{Keywords: semaphorin, plexin, neuropilin, axon guidance, synapse formation}

\section{SEMAPHORINS AND THEIR RECEPTORS}

Semaphorins (Semas), which consist of 20 family members in vertebrates, are one of the largest families of guidance cues. Semaphorins include both secreted and membrane-bound proteins, and they serve a variety of roles in the peripheral and central nervous system (PNS and CNS; reviewed in Mann et al., 2007; Tran et al., 2007; Pasterkamp and Giger, 2009). Semaphorins were first characterized as repulsive guidance cues, and later a role in promoting neuronal growth was identified. In vertebrates, semaphorins are subdivided into five subfamilies, including classes $3,4,5,6$, and 7 (Figure 1). The major receptors for semaphorins are plexins and neuropilins (Figure 1). Plexins and neuropilins consist of nine and two family members in mammals, respectively. Plexins and neuropilins are subdivided into four classes; plexin (Plex) A1-4, B1-3, $\mathrm{C} 1$, and D1, and two classes; neuropilin 1-2 (Npn1-2), respectively. Most class 3 semaphorins bind to Npns, and Npns associate with plexinA family members to transduce Sema3 signals across the neuronal plasma membrane (Takahashi et al., 1999; Tamagnone et al., 1999). Sema3E is an exception and directly binds to PlexD1 (Gu et al., 2005). Other interactions between semaphorins and plexins have also been reported, including the interaction between Sema4D and PlexB1 (Tamagnone et al., 1999), between Sema5A and PlexB3 (Artigiani et al., 2004), between Sema7A and PlexC1 (Tamagnone et al., 1999), among Sema6C/6D and PlexA1 (Toyofuku et al., 2004; Yoshida et al., 2006), and among Sema6A/6B and PlexA2/A4 (Suto et al., 2005; Figure 1). Semaphorins also bind to other receptors in addition to plexins and Npns (Tran et al., 2007). For example, class 4 semaphorins signal through two immune system receptors, CD72 and Tim-2 (Kumanogoh et al., 2000, 2002; reviewed in Kikutani and Kumanogoh, 2003;
Suzuki et al., 2008; Takamatsu and Kumanogoh, 2012). Another example is that the glycosylphosphatidylinositol (GPI)-anchored Sema7A binds to integrin receptors (Pasterkamp et al., 2003). Several reviews cover work over the last two decades on the roles played by semaphorins in the nervous system (Mann et al., 2007; Tran et al., 2007; Pasterkamp and Giger, 2009), so here I focus on recent studies related to neural circuit assembly.

\section{SEMAPHORINS IN GROWTH AND GUIDANCE OF AXONS AND DENDRITES}

\section{PERIPHERAL MOTOR AND SENSORY NEURON PROJECTIONS}

Motor neuron axonal trajectories have been extensively studied in order to understand the cellular and molecular mechanisms underlying the establishment of function of motor circuitry. Vertebrate motor neurons extend axons out of the spinal cord and innervate target skeletal muscles. Along these trajectories, motor axons encounter many axon guidance cues, ultimately finding their appropriate muscle targets, including those that reside within the developing limb. In the ventral spinal cord, cohorts of motor neurons are arrayed in longitudinal columns and project their axons to distinct peripheral regions. Lateral motor column (LMC) neurons are generated only at limb levels, and they extend their axons into the limb mesenchyme. In contrast, the median motor column (MMC) neurons extend their axons to axial muscles.

In both Sema3A and Npn1 mutant mice, peripheral nerves exhibit severe defasciculation and branching defects during embryogenesis (Behar et al., 1996; Kitsukawa et al., 1997; Taniguchi et al., 1997; Gu et al., 2003). Detailed analyses of the roles played by Sema3A-Npn1 and Sema3F-Npn2 signaling in motor axon pathfinding describe how semaphorin signaling participates in 


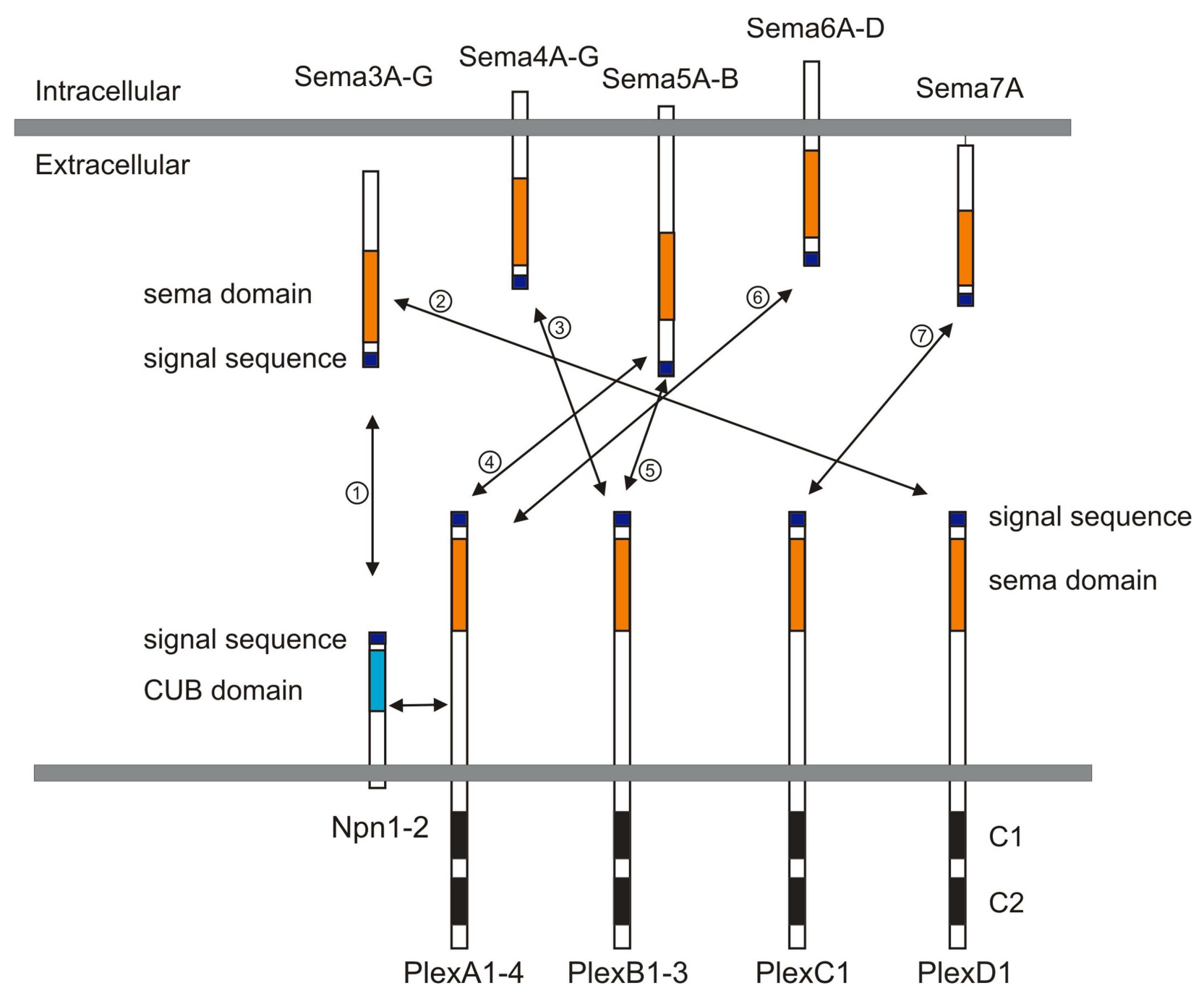

FIGURE 1 | Semaphorins and their receptors (plexins and neuropilins). Semaphorins consist of secreted (class 3), glycosylphosphatidylinositol (GPI)-anchored (class 7), or transmembrane (class 4-6) family members. Neuropilins consist of two transmembrane molecules (Npn1-2), and plexins consist of transmembrane A (1-4), B (1-3), C1, and D1 family members. Most class 3 semaphorins require an obligate neuropilin co-receptor. Sema3E binds to PlexD1 without neuropilins. Class 4 and 5 semaphorins interact with
plexinBs. Class 6 semaphorins interact with plexinAs. Sema7A interacts with PlexC1. CUB indicates complement binding. One to seven indicate the interactions between semaphorins and their receptors; 1 : class 3 semaphorins and neuropilin1/2, 2: Sema3E and PlexD1, 3: Sema4D and PlexB1/B2 or Sema4C/4G and PlexB1, 4: Sema5A/5B and PlexA1/A3, 5: Sema5A and PlexB3, 6: Sema6A/6B and PlexA2/A3 or Sema6C/6D and PlexA1, 7: Sema7A and PlexC1. motor axon targeting (Huber et al., 2005; Huettl et al., 2011). At embryonic day 10.5 (E10.5), Npn1 mRNA is expressed by most LMC neurons, whereas Npn2 is expressed by a subset of the medial LMC (LMCm) motor neurons but not by the motor neurons in the lateral division of the LMC (LMCl; Huber et al., 2005). Expression of Sema3A is detected at E10.5, when spinal nerves have extended into the plexus region but have not yet entered the limb (Huber et al., 2005). This suggests that Sema3A regulates the timing of motor axon ingrowth into the limb. Supporting this idea, precocious extension of motor and sensory projections toward distal forelimb regions is observed in Sema3A null mice and also in $N p n 1^{\text {Sema- }}$ mice, which express a mutant Npn1 protein that is deficient in secreted Sema binding (Gu et al., 2003; Huber et al., 2005). Sema3A is also expressed adjacent to peripheral nerve tracts within the forelimb at E11.5 (Huber et al., 2005), raising the possibility that Sema3A may regulate motor axon fasciculation at later developmental times. Peripheral nerves in $\mathrm{Npn}^{\mathrm{Sema}-}$ and Sema3A mutants also show marked defasciculation and aberrant growth when compared to wild-type (Huber et al., 2005). Sema3F, encoding a Npn2 ligand, is expressed in the dorsal limb bud and so participates in directing Npn2-expressing LMCm axons along a ventral trajectory in the forelimb (Huber et al., 2005). Loss- and gain-of-function experiments reveal that Sema3F-Npn2 signaling is required to direct $\mathrm{LMCm}$ axons along their ventral trajectory (Huber et al., 2005).

A more recent study examines the reciprocal interactions between sensory and motor axons as they navigate along their trajectories and explore the role played by Npn 1 signaling in these 
axon-axon interactions (Huettl et al., 2011). Deletion of Npn1 solely in motor neurons reveals that peripheral sensory projections are still established correctly, even though motor projections are severely defasciculated in the distal limbs (Huettl et al., 2011). Genetic elimination of motor neurons demonstrates that sensory axons require only minimal motor axon scaffolding to establish their projections in the distal limb (Huettl et al., 2011). In contrast, defects in sensory axonal trajectories caused by sensory neuronspecific Npn1 deletion is accompanied by defasciculation of motor axons (Huettl et al., 2011). Thus, motor axons are dependent on sensory axons, and they interact in part through Npn1-mediated fasciculation in the developing limb.

Sema3A is expressed by motor neurons in addition to peripheral tissues. Since the Sema3A receptor Npn1 is also expressed by motor neurons, as described above, it has been a puzzle as to why both $N p n 1$ and Sema3A are both expressed by motor neurons. Using gain-of-function and knockdown approaches in chick, Moret et al. (2007) found that co-expression of Npn1 and Sema3A in motor neurons regulates axon sensitivity to environmental Sema3A sources during motor axon pathfinding. In chick, Sema3 $A$ is expressed by MMC motor neurons at both early and late developmental stages, whereas Sema3A is not expressed by LMC motor neurons at early stages but is expressed when the axons reach the base of the limb (Moret et al., 2007). In contrast, Npn1 is expressed by both MMC and LMC motor neurons (Moret et al., 2007). Premature expression of Sema3A in LMC motor neurons leads motor axons to defasciculate and invade territories they normally avoid, suggesting that Npn 1 becomes insensitive to early ectopic environmental expression of Sema3A (Moret et al., 2007). Moreover, knockdown studies show that Sema3A expression in motor neurons is required for correct spinal nerve compaction and dorsal motor axon extension (Moret et al., 2007). Therefore, Sema3A in motor neurons sets the level of sensitivity of their growth cones to exogenous Sema3A exposure (Moret et al., 2007). This regulation is associated with post-translational and local control of the availability of Npn1 at the growth cone surface (Moret et al., 2007). Thus, the interplay between intrinsic and extrinsic Sema3A may represent a fundamental mechanism in the accurate specification of axon pathways. Future studies will demonstrate this proposed role for neuronal and non-neuronal Sema3A and the regulation of motor axon guidance in mice.

\section{MIDLINE CROSSING OF COMMISSURAL AXONS}

In the spinal cord, commissural neurons, whose cell bodies are located in the dorsal horn, project their axons to the ventral spinal cord. When these axons reach the floor plate, they cross the midline, turn rostrally, extend longitudinally on the contralateral side of the ventral spinal cord and project to the brain. Once commissural axons cross the floor plate, they lose their responsiveness to chemoattractants such as netrin-1, and become responsive to chemorepulsive cues, which include Sema3B and Sema3F (Zou et al., 2000). The molecular mechanisms that allow for this change of responsiveness to these cues have been largely unknown. Recently, two studies define novel mechanisms that may underlie this switch (Nawabi et al., 2010; Parra and Zou, 2010).

Parra and Zou (2010) investigated the mechanisms by which semaphorin repulsion in commissural axons is switched on at the midline. Using a collagen explant assay with pre-crossing commissural neurons, they noted that Sonic Hedgehog (Shh) can activate a novel repulsive response of pre-crossing commissural axons to Sema3B and Sema3F (Parra and Zou, 2010). Blocking Shh activity, or perturbing the Shh receptors Ptch1 and Smo, causes midline guidance defects indicative of a failure of post-crossing commissural axons to respond to Sema3B or Sema3F (Parra and Zou, 2010). The involvement of cyclic nucleotides in this switching event was then examined, since cyclic nucleotides have been shown in vitro to influence signaling in response to guidance cues, and the ratio of cAMP/cGMP regulates axonal attraction or repulsion in vitro (Song et al., 1998). Consistent with these observations, enhancing protein kinase A (PKA) activity in pre-crossing axons diminishes Shh-induced semaphorin-mediated repulsion and causes profound midline stalling and overshooting/wandering of post-crossing axons (Parra and Zou, 2010). Therefore, this study shows that Shh can act as a switch in commissural axon guidance responses to semaphorins by reducing cAMP/PKA signaling.

Nawabi et al. (2010) present another novel mechanism underlying the switch of axon guidance response of commissural axons. PlexA1 has been identified as a co-receptor that along with Npn2 mediates Sema3B responses (Nawabi et al., 2010). Interestingly, PlexA1 protein level is up-regulated by floor plate (FP) signals in commissural growth cones, and these FP signals suppress proteolytic calpain 1 activity to increase PlexA1 protein levels in commissural axons (Nawabi et al., 2010). The FP cue responsible for regulating PlexA1 protein expression was then identified as $\mathrm{Nr}$ CAM (Nawabi et al., 2010). Nr-CAM was considered as a possible candidate due to its high and restricted expression in the FP, and also its function in the regulation of axon growth and guidance during the formation of various commissural tracts (Falk et al., 2005; Williams et al., 2006). A range of in vitro and in vivo experiments reveal that $\mathrm{Nr}$-CAM derived from the FP inhibits PlexA1 processing by blocking Calpain 1 and thus increases growth cone sensitization to Sema3B (Nawabi et al., 2010). These results reveal novel mechanisms for changing the sign of commissural axon responsiveness to semaphorin guidance cues.

\section{RETINAL GANGLION CELL AXON CROSSING AT THE OPTIC CHIASM MIDLINE}

During neural development retinal ganglion cell (RGC) axons must choose to cross or avoid the CNS midline at the optic chiasm, thereby regulating RGC projections to ipsilateral or contralateral retinorecipient targets. Npn1 has recently been shown to guide retinal axon crossing at optic chiasm and, surprisingly, the relevant ligand is not a class 3 semaphorin but VEGF164 (Erskine et al., 2011). Erskine et al. (2011) found that Npn1, but not Npn2, is expressed by mouse RGCs, and that loss of $N p n 1$ increases the proportion of RGC axons that project ipsilaterally. Class 3 semaphorins are not expressed near the optic chiasm, but VEGF is expressed at this midline location (Erskine et al., 2011). Consistent with these expression patterns, a mouse mutant that harbors a Npn1 point mutation which abolishes binding to all class 3 semaphorins (Gu et al., 2003) does not exhibit any defects in RGC axon guidance at the midline (Erskine et al., 2011). However, loss of VEGF164 phenocopies the RGC chiasm crossing defects observed in Npn1 null mutants (Erskine et al., 2011). In vitro analyses reveal 
that VEGF164 is a chemoattractant for RGC axon growth cones (Erskine et al., 2011). Since VEGF is expressed in other regions of the nervous system (Ruhrberg et al., 2002; Schwarz et al., 2004), this study suggests that VEGF164-Npn1 signaling may be involved in controlling axon guidance events in different regions of the CNS.

A very recent study demonstrates that Sema6D thorough its receptors PlexA1 and $\mathrm{Nr}$-CAM promotes retinal axon midline crossing (Kuwajima et al., 2012). The authors found that Sema6D and Nr-CAM are expressed on midline radial glia and PlexA1 on chiasm neurons, and PlexA1 and Nr-CAM are expressed on contralateral RGCs. A series of sophisticated in vitro culture experiments reveal that both PlexA1 and $\mathrm{Nr}$-CAM are required on crossed RGCs for inhibition by Sema6D alone, whereas Sema6D interacting together with PlexA1 and Nr-CAM promotes growth (Kuwajima et al., 2012). Furthermore, they found that Nr-CAM can interact with both Sema6D and PlexA1. Finally, in the absence of Sema6D or both PlexA1 and Nr-CAM in vivo, RGC axons defasciculate, misroute into the caudal diencephalon, and more frequently project into the ipsilateral optic tract (Kuwajima et al., 2012). This study provides a novel mechanism underling midline crossing: accessory recognition proteins expressed by ligandexpressing cells modulate ligand activity. This strategy allows a switch in ligand activity without changing receptor expression on responsive axons (Figure 2).

\section{CORTICOSPINAL TRACT GROWTH AND GUIDANCE}

Several semaphorins are known to repel or attract cortical neurites in vitro (Bagnard et al., 1998; Castellani et al., 2000, 2002; Polleux et al., 2000; Chauvet et al., 2007), but in vivo roles for these capabilities are obscure. Two recent studies begin to address this issue by showing that semaphorin signaling guides corticospinal axons in vivo (Faulkner et al., 2008; Rünker et al., 2008). Faulkner et al. (2008) show that PlexA3 and PlexA4 are expressed in the developing cerebral cortex when corticospinal tract (CST) motor axons originating in cortical layer $\mathrm{V}$ are guided caudally to the spinal cord. Interestingly, Sema6A is expressed along the ventral pyramidal tract and at the pyramidal decussation (Faulkner et al., 2008; Rünker et al., 2008). Sema6A mutants, and also PlexA3/A4 double mutants, have defects in the dorsal extension and crossing of motor corticospinal axons at the pyramidal decussation (Faulkner et al., 2008). When neuronal tracers such as DiI or BDA are bilaterally injected into the Sema6A, or PlexA3/A4 mutant motor cortices, a large DiI-labeled axon bundle diverges from its normal pathway at the pyramidal decussation toward the ventrolateral aspect of the spinal cord, a phenotype never observed in wild-type (Faulkner

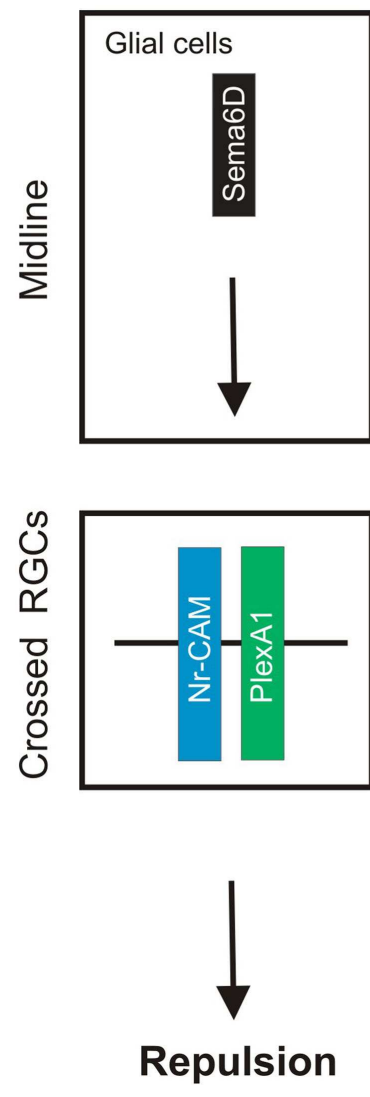

FIGURE 2 | Sema6D controls retinal midline crossing through its interaction with PlexA1 and Nr-CAM. Sema6D and Nr-CAM are expressed by glial cells in the chiasm, and PlexA1 is expressed by SSEA $1^{+}$neurons in the chiasm. $\mathrm{Nr}-\mathrm{CAM}$ and PlexA1 are

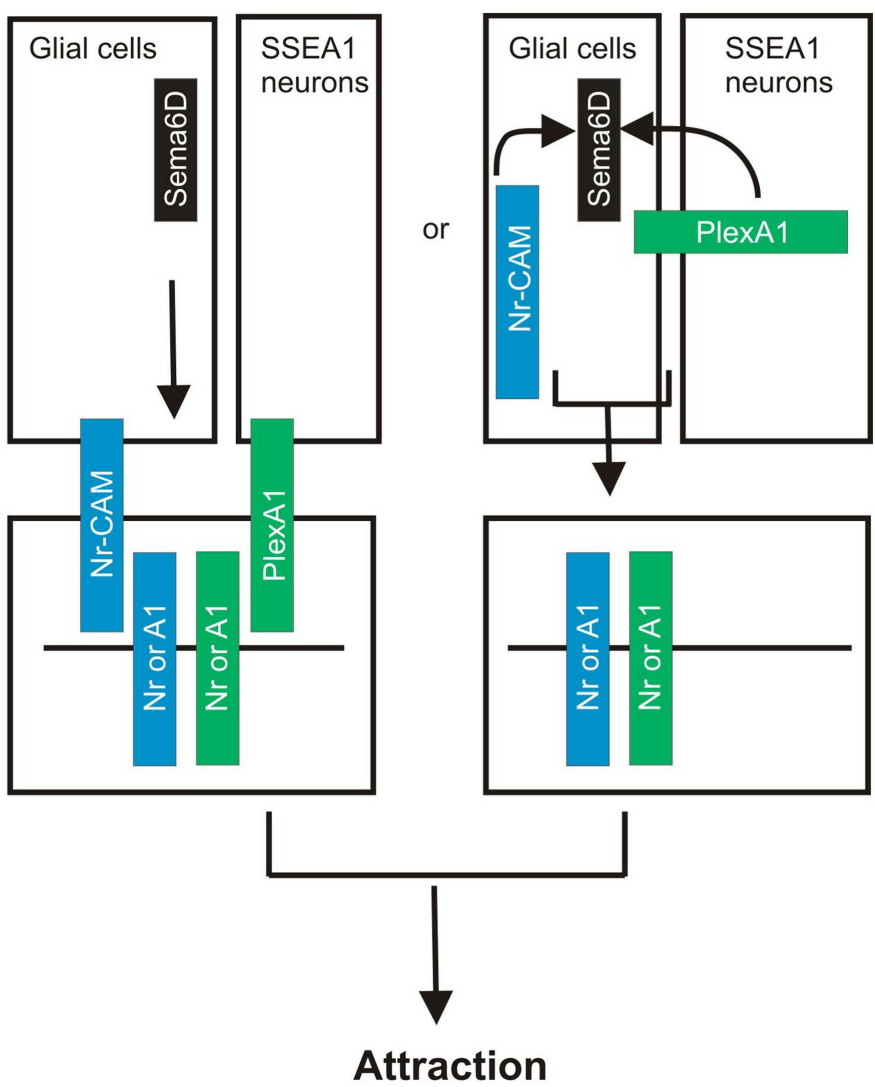

expressed by crossed RGCs. The receptor complex in cis on RGCs and Sema6D alone leads to repulsion of RGCs, whereas the complex on chiasm cells acting in trans with $\mathrm{RGC}$ receptors promotes axonal attraction. 
et al., 2008). These abnormally projecting CST axons in Sema6A or PlexA3/A4 mutants maintain their ipsilateral course at the pyramidal decussation and come to occupy a unique, aberrant, position in the ventrolateral region of the spinal cord (Faulkner et al., 2008). Although Npn1 mutants do not show similar dorsal turning defects, Npn1 is required for proper fasciculation of the tract at midline crossing (Faulkner et al., 2008). Thus, PlexA3/A4 and Npn 1 have distinct functions in controlling CST axon guidance. It will be interesting to examine how defects in fasciculation of Npn1-deficient CST axons will affect CST-circuitry. Similarly, Rünker et al. (2008) show that Sema6A and PlexA4 mouse mutants harbor defects in CST axon guidance at the pyramidal decussation. Although PlexA2 interacts with Sema6A (Suto et al., 2005; Renaud et al., 2008), PlexA2 mutants do not show any apparent defects in CST axon guidance (Rünker et al., 2008). Interestingly, before CST axons reach the pyramidal decussation, Sema6A-deficient mice show guidance defects in CST axons at the mid-hindbrain boundary; this indicates that Sema6A controls CST axon guidance at multiple choice points (Rünker et al., 2008).

\section{CORPUS CALLOSUM GROWTH AND GUIDANCE}

The corpus callosum (CC) is the main pathway responsible for interhemispheric communication in the brain. Neurons that project through the CC are located in upper and lower cortical layers (Yorke and Caviness, 1975; Porter and White, 1983). Niquille et al. (2009) have shown that CC neuronal populations exert an attractive influence on callosal axons, which is mediated by both GABAergic and glutamatergic calretinin (CR)-positive neurons. Sema3C was identified as a candidate cue for mediating this attractive activity based on its expression pattern; Sema3C mRNA is restricted to CR-positive glutamatergic neurons (Niquille et al., 2009). Sema3C loss of function and knockdown of Npn1 reveal that Sema3C-Npn1 signaling contributes to the chemoattractive effect of CR-positive glutamatergic neurons on callosal axons (Niquille et al., 2009).

\section{AXON ORGANIZATION AND NEURAL MAP TOPOGRAPHY IN OLFACTORY SYSTEM}

In the mouse olfactory system, each olfactory sensory neuron (OSNs) expresses only one of many possible functional odorant receptors (ORs; reviewed in Mombaerts, 2006; Mori and Sakano, 2011). OSN axons expressing the same OR converge on a specific target region, the glomerulus, within the olfactory bulb (OB; reviewed in Mombaerts, 2006; Mori and Sakano, 2011). Recently, two studies demonstrate that both Sema3A-Npn1 and Sema3FNpn2 signaling are involved in specifying neural map topography in the OB (Imai et al., 2009; Takeuchi et al., 2010). Previous studies show that OR-specific cAMP signaling defines a gradient of Npn1 expression (Imai et al., 2006), but how Npn1 controls topographic map formation was still unclear. Imai et al. (2009) show, using loss- and gain-of-function experiments, that Npn1 expression levels determine glomerular positioning along the anterior-posterior axis of the OB. Interestingly, instead of axon-target interactions, Npn1 regulates the sorting of OSN axons within the olfactory nerve (Imai et al., 2009). In fact, axon-target interactions appear not to be required for generating anterior-posterior topography, since Gli3 mutant mice, in which the OB is completely absent, do not show obvious defects in topography along the A/P axis (Imai et al., 2009). OSN-specific knockout of Sema3A reveals that expression of Sema3A in OSNs is required for pre-target axon sorting in the nerve bundle (Imai et al., 2009). More recent work, also from Sakano's laboratory, demonstrates that Sema3F-Npn2 signaling regulates the topographic patterning of OSNs along the dorsalventral axis of the OB (Takeuchi et al., 2010). In the OBs, Npn2 in the axon termini of OSNs forms a gradient in the OB with high levels ventrally and low levels dorsally (Takeuchi et al., 2010). Lossand gain-of-function analyses reveal a cell-autonomous function for Npn2/PlexA3 in establishing the OSN projection along the dorsal-ventral (D-V) axis (Takeuchi et al., 2010). Interestingly, Sema3F transcript is not expressed in the OB but in the olfactory epithelium (OE; Takeuchi et al., 2010). Further, Sema3F was found to be secreted by early-arriving OSN axons and deposited at the anterodorsal OB to repel later-arriving Npn2-positive axons (Takeuchi et al., 2010). Therefore, sequential arrival of OSN axons, together with the graded and complementary expression of Npn2 and Sema3F by OSNs, are required for appropriate topographic projections along the $\mathrm{D}-\mathrm{V}$ axis (Takeuchi et al., 2010). These two studies demonstrate novel mechanisms of how axonal sorting in the nerves prior to targeting is important and how distinct secreted semaphorins expressed on axons influence follower axons. This framework for complex topographic organization may be used in other regions of the mammalian nervous system.

\section{THALAMOCORTICAL CONNECTIONS}

Mice harboring mutations in various semaphorin signaling components are not only useful for understanding the molecular mechanisms underlying neural circuit formation but they can also lend insight into adult neural plasticity, if they are viable. Recent work has examined specificity and plasticity of thalamocortical connections in Sema6A mutant mice (Little et al., 2009). Despite the defect in thalamic projections in Sema6A mutants (Leighton et al., 2001; Little et al., 2009), Sema6A mutants survive until adulthood, providing a unique model that has normal cortical patterning but defects in thalamic inputs. Interestingly, the early embryonic shift in thalamocortical axon connectivity observed at E16.5 and P0 in Sema6A mutants is partially recovered at P4, and completely compensated for in adult Sema6A mutants (Little et al., 2009). The misrouted axons are apparently able to find their way to the visual cortex via alternative pathways at postnatal stages so as to reestablish a normal pattern of thalamocortical connectivity (Little et al., 2009). The authors also observed a significant reduction in the size of the dorsal lateral geniculate nucleus (dLGN) in Sema6A-deficient brains compared to wild-type brains (Little et al., 2009). This suggests that some dLGN neurons whose axons do not reach their target regions may die during development. Therefore, it seems that some misrouted axons die and some can find their targets via alternative pathways. Together, these findings demonstrate the robust capacity of the early postnatal cortex for remapping initial sensory inputs following experience.

\section{DENDRITIC PROCESS OUTGROWTH IN THE SPINAL CORD}

Like axons, dendritic morphology includes growth, targeted extension, and branching, all of which must be precisely regulated during development (reviewed in Jan and Jan, 2003). For example, 
Sema3A is implicated in dendritic growth and orientation of cortical pyramidal neuron subtypes (Polleux et al., 2000; Fenstermaker et al., 2004).

Specific motor neuron pools exhibit distinct dendritic arbor morphologies that are critical for their ability to receive and process various types of synaptic input (Landmesser, 1978; Okado et al., 1990; Vrieseling and Arber, 2006). The transmembrane semaphorin Sema6A and its receptor, PlexA4 regulate dendritic growth of motor neuron subtypes by modulating a downstream signaling molecule, FERM Rho-GEF protein FARP1, in the developing spinal cord (Zhuang et al., 2009). FARP1 is expressed by LMC, but not MMC, motor neurons in chick, and FARP1 protein is detected on the dendrites (Zhuang et al., 2009). Ectopic expression and knockdown approaches demonstrate that FARP1 is necessary and sufficient to regulate the dendrite process length of LMC motor neurons (Zhuang et al., 2009). FARP2, a protein related to FARP1, binds to all plexinA family members (Toyofuku et al., 2005), whereas FARP1 interacts strongly with PlexA4 but associates only very weakly with PlexA1 (Zhuang et al., 2009). Gain-of-function and knockdown approaches for Sema6A and PlexA4 show results similar to those observed following similar manipulations of FARP1, suggesting that FARP1 lies downstream of Sema6A-PlexA4 signaling (Zhuang et al., 2009). Thus, Sema6A controls columnar-specific dendritic growth through the action of FARP1, suggesting that distinct semaphorin-plexin signaling may also be involved in regulating dendritic morphology of motor neuron pools and other CNS neurons.

\section{SEMAPHORINS IN CELLULAR-CIRCUIT LAMINATION RETINAL LAMINATION AND FUNCTION}

Specific patterns of synaptic connections in many regions of the nervous system are organized within laminae. One of the most best studied laminar structures found in the vertebrate nervous system is the retina. In the vertebrate retina, distinct subtypes of RGCs, amacrine cells (ACs), and bipolar cells (BCs) make synaptic connections within specific synaptic plexus of the inner plexiform layer (IPL), a laminar structure that is conventionally divided into 5-10 sublaminae (reviewed in Wässle, 2004; Sanes and Zipursky, 2010). Recently, two studies using mouse genetics demonstrate that different classes of transmembrane semaphorins regulate select aspects of retinal lamination and function in the mammalian retina (Matsuoka et al., 2011a,b). Though previous reports showed that certain semaphorins, Npns, and plexins are expressed in the developing mammalian retina (Leighton et al., 2001; de Winter et al., 2004), how semaphorin signaling regulates retinal development and circuit assembly was not known. Matsuoka et al. (2011a) investigated the in vivo roles of semaphorin signaling components in retinal development by analyzing mice that lack each plexin and neuropilin. Through an extensive phenotypic analysis of the mutant mice, the authors found that dopaminergic ACs and M1type melanopsin intrinsically photosensitive retinal ganglion cells (ipRGCs), both of which exhibit neurite stratification predominantly within the S1 sublamina of the IPL in wild-type retinas, extend aberrant processes into S4/S5 in PlexA4-deficient retina (Matsuoka et al., 2011a; Figure 3A). Since PlexA4 is expressed by dopaminergic ACs but not by M1-type ipRGCs, this result suggests that the M1-type ipRGC dendritic stratification deficit within the
IPL of PlexA4-deficient retina is likely a secondary consequence of defects in AC stratification within the IPL of the PlexA4-deficient retina, providing further support for ACs directing RGC dendritic stratification in the IPL (Stacy and Wong, 2003; Mumm et al., 2006; Matsuoka et al., 2011a). Sema6A and its receptor PlexA4 exhibit complementary protein expression patterns within the IPL, suggesting that Sema6A functions as a repulsive barrier within the IPL for neuronal processes expressing PlexA4 (Matsuoka et al., 2011a). Sema6A mutants show the same defects in neurite stratification within the IPL as observed in PlexA4 mutants (Matsuoka et al., 2011a; Figure 3A). Thus, these results show that Sema6A is a functional ligand for PlexA4, required for regulating select retinal neurite stratification in vivo (Matsuoka et al., 2011a; Figure 3A).

A more recent study shows that the transmembrane semaphorins Sema5A and Sema5B serve as repulsive molecules that together constrain neurites of most, if not all, inner retinal neurons to the IPL, serving a role in regulating retinal stratification that is distinct from Sema6A (Matsuoka et al., 2011b; Figure 3B). Sema $5 A$ and Sema5B are both expressed in the outer neuroblastic layer (ONBL) at postnatal day $0(\mathrm{P} 0)-\mathrm{P} 3$, and expression becomes more restricted to the middle and then to the outer part of the inner nuclear layer (INL) at later developmental stages (Matsuoka et al., 2011b). Sema5A-I-; Sema5B ${ }^{-1-}$ mice exhibit severe defects in the stereotypic neurite arborization of multiple AC and RGC subtypes (Matsuoka et al., 2011b; Figure 3B). For example, in Sema5 $A^{-l-}$; Sema $5 B^{-1-}$ mice, multiple subtypes of ACs and RGCs extend neurites toward the ONBL, suggesting that Sema5A and Sema5B prevent ACs and RGC subtypes from elaborating processes in the direction of the ONBL (Matsuoka et al., 2011b). However, dendritic stratification of ipRGC subtypes, which project into distinct IPL sublaminae, are disrupted in Sema $5 A^{-1-}$; Sema $5 B^{-1-}$ mice within the outer (OFF) layers, but not in within the inner $(\mathrm{ON})$ layers (Matsuoka et al., 2011b). Similarly, various AC and BP cell types also show defects in stratification that are more prominent in the ON, as compared to the OFF, layers of the IPL (Matsuoka et al., 2011b; Figure 3B). Therefore, Sema5A and Sema5B constrain stratification of multiple retinal cell types within the IPL in vivo and, importantly, play a more prominent role in regulating stratification within the OFF, as compared to the ON, layers of the IPL. Intriguingly, electrophysiological recordings of light responses from neurons in the GCL of Sema5A ${ }^{-/-}$; Sema $5 B^{-l-}$ retinas ex vivo demonstrates that the OFF pathway is specifically impaired in Sema5A $A^{-1-}$; Sema5B ${ }^{-1-}$ mice, consistent with the selective disruption in OFF layer neuronal stratification in the Sema5A ${ }^{-1-}$; Sema5B ${ }^{-1-}$ IPL (Matsuoka et al., 2011b). Which receptors mediate these Sema5A- and Sema5B-evoked repulsive signaling? Although PlexB3 binds to Sema5A in vitro (Artigiani et al., 2004), PlexB3 ${ }^{-1-}$ mice do not show similar retinal defects as are observed in Sema5A $A^{-1-}$; Sema5B $B^{-l-}$ mice (Matsuoka et al., 2011b). Examination of plexin and Npn expression patterns in the developing retina revealed that PlexA1 and PlexA3 both show expression patterns that are identical and are complementary to the Sema5A/5B expression observed the developing postnatal retina (Matsuoka et al., 2011b). In addition, $\mathrm{PlexA1}^{-I-} ; \mathrm{PlexA3}^{-/-}$ mice phenocopy the inner retinal lamination defects observed in Sema $5 A^{-1-}$; Sema $5 B^{-1-}$ mice (Matsuoka et al., 2011b; Figure 3B). In vitro experiments using retinal cells isolated from $\mathrm{PlexA1}^{-1-}$; 
A

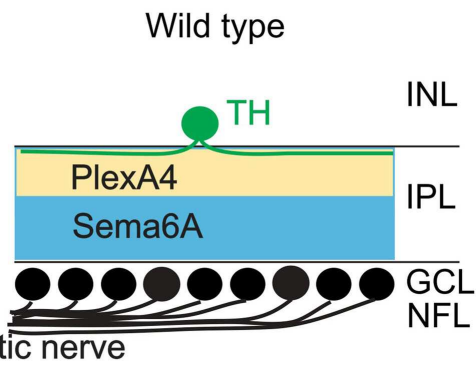

\section{Sema $6 A^{-/-}$or PlexA4 ${ }^{-/-}$}

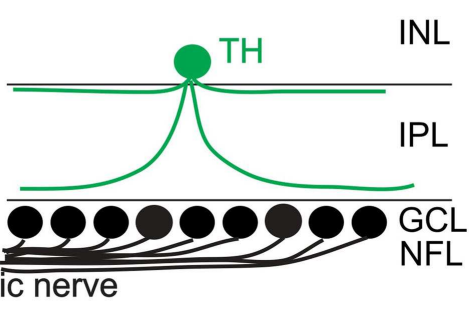

B Wild type

Optic nerve

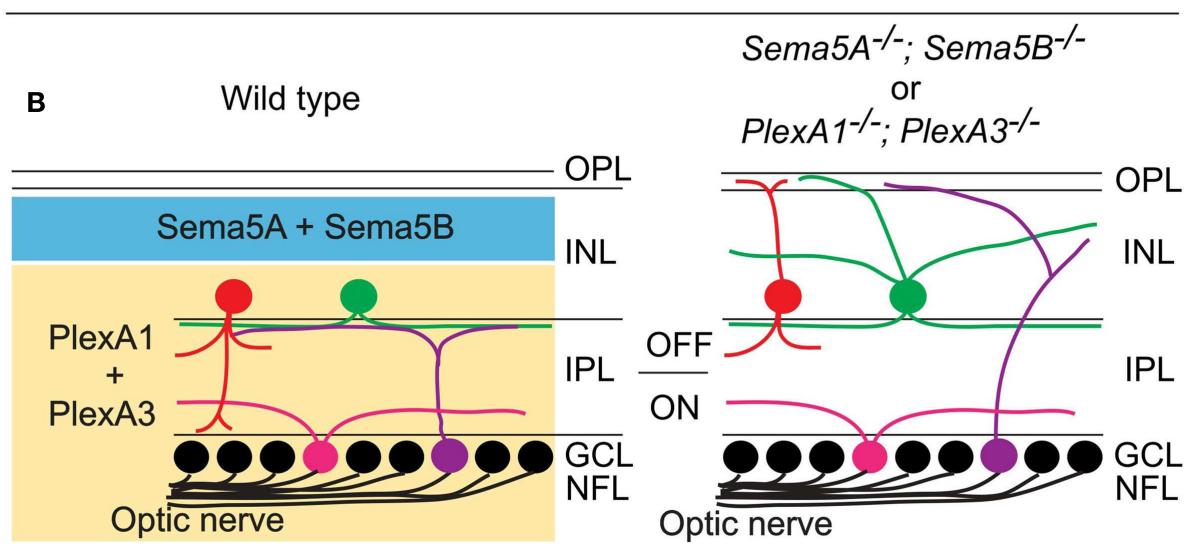

FIGURE 3 | Class 5 and class 6 transmembrane semaphorin signaling through plexinAs governs laminar targeting of inner retinal neuron subtypes. (A) Sema6A and PlexA4 show complementary protein expression in the ON and OFF layers of the inner plexiform layer, and this repulsive signaling confines neurite extension of dopaminergic amacrine cells $\left(\mathrm{TH}^{+}\right)$within the S1 sublamina in wild-type mice. In Sema6A or
PlexA4 mutant mice, dopaminergic amacrine cells extend their aberrant processes to the S4/S5 sublaminae. (B) During early postnatal retinal development, Sema5A/5B and PlexA1/A3 expressions are found in a complementary pattern in the retina. Loss of Sema5A/5B or plexA1/A3 results in neurite mistargeting of multiple inner retinal neuron subtypes into the outer retina.
PlexA $3^{-1-}$ retinas demonstrate that PlexA1 and PlexA3 receptors indeed mediate Sema5A and Sema5B inhibitory signaling (Matsuoka et al., 2011b). Therefore, Sema5A and Sema5B expressed in the ONBL provide repulsive guidance signals to extending neurites from PlexA1/A3-expressing ACs and RGC subtypes in the INBL, and Sema5A/5B-PlexA1/A3 signaling is required for the establishment of specific retinal function.

\section{LAMINA-RESTRICTED PROJECTIONS OF HIPPOCAMPAL MOSSY FIBERS}

The hippocampus is also an ideal model system to study cellular and molecular mechanisms underlying laminar-specific axonal targeting. Pyramidal cells, the principal neurons of the cornu ammonis (CA), receive inputs from many regions in the brain. For example, hippocampal mossy fibers project preferentially to the stratum lucidum, the proximal-most lamina of the suprapyramidal region of CA3. However, the molecular mechanisms underlying these lamina-restricted axonal projections remained unknown. Recently, two studies showed that class 6 semaphorin signaling through plexinA family members controls lamina-restricted projections of hippocampal mossy fibers (Suto et al., 2007; Tawarayama et al., 2010). Suto et al. (2007) focused on PlexA2-1and PlexA4 $4^{-1-}$ mice. In wild-type mice, mossy fibers invade the stratum lucidum in the suprapyramidal region of CA3 and CA3c, whereas PlexA2-deficiency in mice causes a shift of mossy fibers from the suprapyramidal region to the infra- and intrapyramidal regions (Suto et al., 2007). In contrast, in PlexA4 ${ }^{-1-}$ mice, mossy fibers invade most CA3 regions, in particular the stratum lacunosum-moleculare and the stratum oriens, and to a lesser extent the stratum radiatum (Suto et al., 2007). Immunohistochemical analysis shows that PlexA2 is localized on pyramidal cell dendrites, but not on mossy fibers, and that PlexA4 is localized on mossy fibers. This suggests that PlexA2 functions in CA3 pyramidal neurons and PlexA4 in mossy fibers to regulate laminar projections of mossy fibers (Suto et al., 2007). Co-culture experiments using dentate gyrus and CA3brain slices support this idea (Suto et al., 2007). These defects in PlexA4 ${ }^{-1-}$ mossy fiber projections suggest that PlexA4-deficient mossy fibers may lose their responsiveness to a repulsive cue. Although Sema6A binds to PlexA4 (Suto et al., 2005), Sema6A mutants do not show any defects in mossy fiber projections (Suto et al., 2007). Surprisingly, normal mossy fiber projections are restored in PlexA2/Sema6A double mutant mice, suggesting that Sema6A-mediated mossy fiber repulsion is attenuated by PlexA2 expressed in the proximal part of the suprapyramidal region of CA3, allowing mossy fibers to invade this area (Suto et al., 2007).

Other work from Fujisawa's group reveals roles of Sema6B in mossy fiber projections (Tawarayama et al., 2010). Sema6B is expressed in CA3 and repels mossy fibers, and this is dependent on the PlexA4 receptor in vitro (Tawarayama et al., 2010). 
Sema6B-deficient mossy fibers aberrantly project to the stratum radiatum and the stratum oriens (Tawarayama et al., 2010). Furthermore, there are more severe defects in mossy fiber projections in Sema6 $A^{-1-}$; Sema6B $B^{-1-}$ mice compared to either single mutant alone (Tawarayama et al., 2010), suggesting that Sema6A and Sema6B can compensate for each other. PlexA2 promotes the growth of mossy fiber projections in vitro but does not suppress the Sema6B response as it does the Sema6A response (Tawarayama et al., 2010). Thus these two studies reveal that the PlexA4 expression on mossy fibers prevents them from entering the Sema6Aexpressing suprapyramidal region of CA3 and restricts them to the proximal-most region, whereas Sema6A, but not Sema6B, repulsive activity is attenuated by PlexA2 (Suto et al., 2007; Tawarayama et al., 2010). Moreover, both in vivo and in vitro studies show that PlexA2 controls attraction of mossy fibers (Tawarayama et al., 2010). It will be interesting to investigate how PlexA2 actually promotes growth of mossy fibers.

\section{SEMAPHORINS IN PROLIFERATION, DIFFERENTIATION, NEURONAL MIGRATION, AND POLARIZATION THE BOUNDARY BETWEEN THE CENTRAL AND PERIPHERAL NERVOUS SYSTEM}

The CNS is segregated from the PNS by boundaries. In the spinal cord this segregation is evident at the ventral and dorsal root transitional zones. These are located at the motor exit point (MEP), where motor axons leave the spinal cord, and at the dorsal root entry zone (DREZ), where sensory axons enter the spinal cord. Boundary cap (BC) cells at the MEP prevent the emigration of motor neurons from the ventral spinal cord (Vermeren et al, 2003). Ablation of BC cells causes the ectopic positioning of motor neuron cell bodies along their axons and into the ventral nerve roots (Vermeren et al., 2003). Semaphorin-plexin signaling is also involved in establishing this segregation between CNS and PNS (Bron et al., 2007; Mauti et al., 2007). Sema6A is expressed in BC cells, and deletion of Sema6A in mice (Bron et al., 2007), or downregulation of Sema6A (Mauti et al., 2007) in chick, results in ectopic motor neuron cell bodies distributed along the ventral roots. Since class 6 semaphorins bind to plexinA family members (Toyofuku et al., 2004; Suto et al., 2005; Yoshida et al., 2006), a possible role for plexinA receptors in this process was investigated. Knockdown of PlexA1 (Mauti et al., 2007) or PlexA2 (Bron et al., 2007) cause similar defects. Npn2 mutant mice also show a similar phenotype (Bron et al., 2007). Although it is still not clear which plexinA family member is required for Sema6A signaling in mice, these two studies suggest that Sema6A/plexinA/Npn2 signaling constrains spinal motor neuron migration at the MEP. Since Sema6A is also expressed in BC cells at the DREZ, possible roles for several semaphorins and plexins were also examined (Mauti et al., 2007). Knockdown of Sema6A, PlexA1, PlexA4 or Sema6D, indeed, causes failure of dorsal roots to form and segregate properly (Mauti et al., 2007), indicating that semaphorin-plexin signaling also functions in the DREZ as well as in the MEP.

\section{NEURONAL MIGRATION}

Semaphorins also play key roles in controlling neuronal migration. For example, class 3 semaphorins regulate interneuron migration from the basal forebrain within in the tangential migratory stream
(Marín et al., 2001). In addition to tangential migration, a recent work shows that Sema3A can control radial migration (Chen et al., 2008). In the cortex, Sema3A is expressed in a gradient across the cortical layers and its receptor, $N p n 1$, is expressed by migrating neurons (Chen et al., 2008). Knockdown or deletion of Npn1 in newborn cortical neurons by in utero electroporation causes defects in their radial migration (Chen et al., 2008). Although cell fate apparently does not change, their radial orientation during migration is disrupted (Chen et al., 2008). Furthermore, disrupting the Sema3A gradient causes neuronal misorientation in cultured cortical slices (Chen et al., 2008). Interestingly, cortical slice culture experiments show that Sema3A is attractive, but not repulsive, to radially migrating neurons (Chen et al., 2008).

In addition to class 3 semaphorins, a class 6 semaphorin also controls neuronal migration (Kerjan et al., 2005). Cerebellar granule cell precursors migrate tangentially over the cerebellar plate to form the external granular layer (EGL; Wingate, 2001). Postmitotic granule cells migrate tangentially in all directions in the deeper EGL (Ryder and Cepko, 1994; Komuro et al., 2001). Sema6A is expressed in the deeper EGL in the postnatal cerebellar cortex, and granule cell migration within the EGL, or from the EGL, is perturbed in Sema6A mutants; no obvious defects in granule cell proliferation, differentiation, or survival are observed in Sema6A mutants (Kerjan et al., 2005). To determine whether Sema6A functions as a receptor or a ligand, mouse Sema6A mutant chimeras were analyzed, and the results reveal a non-cell-autonomous Sema6A function in granule cells, suggesting that Sema6A functions as a ligand (Kerjan et al., 2005). A more recent study, also from Chédotal laboratory, reveals that PlexA2 is a functional receptor for the Sema6A ligand to regulate granule cell migration (Renaud et al., 2008). The authors found defects in granule cell migration in PlexA2 $2^{-I-}$ mice, which is very similar to those observed in Sema6A ${ }^{-1-}$ mice (Renaud et al., 2008). Genomewide $N$-ethyl- $N$-nitrosourea (ENU) mutagenesis screen identified NMF454 mutant mice, and the single mutation of PlexA2 gene was identified (Renaud et al., 2008). This single nucleotide mutation causes a replacement of an amino acid residue in the semaphorin domain, and this mutant protein cannot bind to Sema6A in vitro (Renaud et al., 2008). Then centrosome-nucleus uncoupling was examined in the absence of Sema6A-PlexA2 signaling, since in cerebellar granule cells, microtubules linked to the centrosome pull the nucleus during migration. In vitro experiments using EGL explants show that there are defects in the distance between the centrosome and the nucleus in Sema6A $A^{-I-}$ and PlexA2 $2^{-I-}$ mice (Renaud et al., 2008). In addition, in vivo analyses reveal that nucleus-centrosome coupling is perturbed in the absence of Sema6A-PlexA2 signaling (Renaud et al., 2008). These studies suggest that Sema6A-PlexA2 signaling modulates neuronal cell migration by controlling centrosome positioning.

\section{PROLIFERATION AND DIFFERENTIATION}

Although Sema6A-PlexA2 signaling does not regulate proliferation and differentiation for granule cells, PlexB2 signaling is required for both proliferation and differentiation (Friedel et al., 2007). PlexB2 is expressed by proliferating granule cells, and PlexB2-deficiency causes a disorganization of the timing of granule cell proliferation and differentiation in the EGL (Friedel 
et al., 2007). Further in vitro and in vivo studies show that Sema4C and Sema4G are likely to be in vivo ligands for PlexB2 (Maier et al., 2011). Although Sema4C ${ }^{-/-}$; Sema4G ${ }^{-/-}$mice show defects in the EGL, the phenotype is less severe compared to that observed in PlexB2-l- mice (Maier et al., 2011), suggesting that other ligands for PlexB2 exist. Together, distinct semaphorin-plexin signaling regulates proliferation, differentiation, and neuronal migration in the EGL.

\section{NEURONAL POLARIZATION}

Neuronal polarization in the form of axon and dendrites is critical for neuronal function. Two studies recently show that Sema3A signaling controls the decision made by newly extending neurites to become axons or dendrites (Nishiyama et al., 2011; Shelly et al., 2011). Nishiyama et al. (2011) show that overexpression in vitro of Sema3A in Xenopus spinal commissural interneurons (xSCINs) converts axons to dendrites, and this conversion of neurite identity requires the voltage-dependent $\mathrm{Ca}^{2+}$ channel $\mathrm{Ca}_{\mathrm{v}} 2.3$. Sema3A expression is apparently required for $\mathrm{Ca}_{\mathrm{v}} 2.3$ expression in vivo, and a series of electrophysiological analyses in vitro suggest that Sema3A is likely to increase the number of $\mathrm{Ca}_{\mathrm{v}} 2.3$ in the growth cone plasma membrane rather than modulating their gating properties (Nishiyama et al., 2011). Moreover, downregulation of $\mathrm{Ca}_{\mathrm{v}} 2.3$ expression reveals that $\mathrm{Ca}_{\mathrm{v}} 2.3$ is required for acquisition of the dendrite identity similar to Sema3A, so Sema3A-Ca 2.3 signaling is required for dendrite identity in vivo (Nishiyama et al., 2011). Finally, cGMP signaling induces $\mathrm{Ca}_{\mathrm{v}} 2.3$ expression and dendrite identity (Nishiyama et al., 2011). Taken together, this study suggests that Sema3A induces the cGMP-mediated expression of functional $\mathrm{Ca}_{\mathrm{v}} 2.3$ channels, recruits $\mathrm{Ca}_{\mathrm{v}} 2.3$ channels to the growth cone plasma membrane, and promotes the acquisition of the dendrite identity. The molecular mechanisms of how Sema3A recruits $\mathrm{Ca}_{\mathrm{v}} 2.3$ channels to the plasma membrane and how $\mathrm{Ca}_{\mathrm{v}} 2.3$ regulates dendrite identify will be examined in future studies.

Similarly, Shelly et al. (2011) show that local exposure to Sema3A promotes dendrite formation and suppresses axon formation in cultured hippocampal neurons. Knockdown experiments show that Npn1 is required for this neuronal polarization. Using FRET sensors expressed in cultured hippocampal neurons, the authors show that Sema3A induces a gradual elevation of cGMP levels and also a concomitant reduction in cAMP levels and PKA activity (Shelly et al., 2011). A previous work shows that axon initiation triggered by a cAMP analog or BDNF requires PKAdependent phosphorylation of LKB1, a serine/threonine kinase that is essential for axon formation (Shelly et al., 2007), and also phosphorylation of GSK-3 $\beta$, a crucial axon determinant (Shelly et al., 2010). Sema3A signaling, which promotes dendrite formation, antagonizes PKA-dependent phosphorylation of LKB1 and GSK-3 $\beta$, consistent with the crucial role of these kinases in axon formation (Shelly et al., 2011). Finally, perturbing Sema3A signaling in newly generated cortical neurons in the rat embryo suggests that Sema3A signaling is indeed required for axon/dendrite polarization in vivo (Shelly et al., 2011). This study suggests that Sema3A regulates axon/dendrite polarity by suppressing axon-specific cAMP/PKA-dependent processes and promoting dendrite-specific cGMP/PKG-dependent functions.

\section{SEMAPHORINS IN SYNAPSE FORMATION AND FUNCTION SYNAPSE FORMATION IN VITRO AND EX VIVO}

In addition to the guidance of axons and dendrites, recent studies show that semaphorins also control synapse formation and synaptic function. An RNAi-based candidate screen found that Sema4B and Sema4D are involved in synapse development (Paradis et al., 2007). It was shown that Sema4B affects the formation of both GABAergic and glutamatergic synapses, whereas Sema4D affects formation of GABAergic, but not glutamatergic, synapses (Paradis et al., 2007). Furthermore, two additional studies show that semaphorins modulate synaptic function (Sahay et al., 2005; Bouzioukh et al., 2006). First, co-receptors for secreted semaphorins, Npns, are found at synapses (Sahay et al., 2005; Bouzioukh et al., 2006). Furthermore, application of Sema3F to acute hippocampal slices modulates both the frequency and amplitude of miniature EPSCs in granule cells of the dentate gyrus and CA1 (Sahay et al., 2005). Similarly, acute application of Sema3A decreases the efficacy of synaptic transmission evoked in the CA1 region of hippocampal slices (Bouzioukh et al., 2006). These studies reveal that semaphorins function in adult brains as well as the developing nervous systems.

\section{REGULATION OF SYNAPSE NUMBER, DENDRITIC PROCESS AND SPINE MORPHOLOGY}

Class 3 and 4 semaphorins have roles in synapse formation and function in vitro or ex vivo as mentioned above (Sahay et al., 2005; Bouzioukh et al., 2006; Paradis et al., 2007). However, in vivo roles of semaphorins in synaptogenesis remained less clear. Tran et al. (2009) showed that Sema3A/Npn1/PlexA4 and Sema3F/Npn2/PlexA3 signaling regulate CNS connectivity through the differential control of spine morphogenesis, synapse formation, and the elaboration of dendritic morphology. In Sema $3 \mathrm{~F}^{-1-}$ and $\mathrm{Npn} 2^{-1-}$ mice, abnormal spine morphology and increased spine number and adult dentate gyrus (DG) granule cells (GCs) are observed at P21 (Tran et al., 2009). Similarly, both aberrant spine distribution and changes in spine morphology were observed on apical, but not basal, dendrites of layer $\mathrm{V}$ cortical pyramidal neurons in Sema3 $F^{-1-}$ and $N p n 2^{-1-}$ mice (Tran et al., 2009). Furthermore, whole-cell voltage-clamp recordings reveal that mEPSCs in layer V pyramidal neurons and DG GCs in acute brain slices exhibit increased frequency, no change in amplitude, however no defects in the paired-pulse amplitude ratio in $\mathrm{Npn} 2^{-/-}$ mice were observed. This suggests that the increase in mEPSC frequency found in $N p n 2^{-/-}$mice is due to an increase in the number of synapses, rather than an increase in the probability of presynaptic release (Tran et al., 2009). Similar defects are observed in PlexA3 mutants. Thus, Sema3F/Npn2/PlexA3 signaling negatively regulates both excitatory synapse number and synaptic transmission in layer V and DG neurons. Furthermore, $N p n 1^{\text {Sema- }}$ mice exhibit markedly reduced growth and branching of layer $\mathrm{V}$ cortical neuron basal, but not apical, dendritic arborizations, indicating that Sema3A-Npn1 signaling positively regulates dendrite growth and branching (Tran et al., 2009). Similar defects are observed in PlexA4 mutants (Tran et al., 2009). Consistent with the distinct defects observed in the absence of Sema3F/Npn2/PlexA3 and Sema3A/Npn1/PlexA4 signaling, cell surface Npn2 receptor is predominantly localized to the primary apical dendrite in 
cultured cortical neurons with pyramidal morphology, whereas the Npn1 receptor is more uniformly distributed on all dendritic processes (Tran et al., 2009). Taken together, these finding demonstrate that Sema3F/Npn2/PlexA3 signaling controls differential spine growth and distribution, and Sema3A/Npn1/PlexA4 signaling controls basal dendrite growth. It will be of interest to determine if other guidance receptors exhibit localization to dendritic subdomains, since this could provide a robust mechanism for segregating complex circuit organization in the CNS.

\section{SENSORY-MOTOR CIRCUIT FORMATION IN THE SPINAL CORD}

In the vertebrate somatosensory system, peripheral stimuli are conveyed by dorsal root ganglia (DRG) sensory neurons. DRG sensory neurons fall into two major groups: those transducing proprioceptive and cutaneous sensory stimuli (Brown, 1981; Koerber and Mendell, 1992). Proprioceptive neurons convey information about the state of muscle contraction and limb position, whereas cutaneous neurons mediate a wide range of noxious and innocuous stimuli (Brown, 1981; Koerber and Mendell, 1992). The myelinated axons of proprioceptive sensory neurons avoid the superficial dorsal horn and project to the intermediate or ventral spinal cord, while the axons of cutaneous afferents project directly into the superficial dorsal horn (Brown, 1981; Koerber and Mendell, 1992). Signals mediated by Sema3A have been suggested to inhibit cutaneous axons in the ventral spinal cord (Messersmith et al., 1995; Fu et al., 2000). However, genetic inactivation of Sema3A in mice has yet to reveal a major role for these ligands in the patterning of sensory axonal trajectories (Behar et al., 1996; Taniguchi et al., 1997; Gu et al., 2003). Nevertheless, other semaphorins belonging to several classes are expressed in the spinal cord (Cohen et al., 2005), and a second major class of semaphorin receptors, the plexins are expressed by sensory and spinal neurons (Cheng et al., 2001; Cohen et al., 2005), raising the possibility plexins are important for establishing central spinal sensory afferent trajectories.

Two studies on the role of the PlexA1 receptor and its ligand Sema6D demonstrate that Sema6D-PlexA1 signaling controls axon positioning of proprioceptive sensory neurons in the dorsal spinal cord (Yoshida et al., 2006; Leslie et al., 2011; Figure 4A). PlexA1 is exclusively expressed by proprioceptive sensory neurons in the DRG, and Sema6D is expressed in the dorsal spinal cord (Yoshida et al., 2006). In PlexA1 or Sema6D mutants, proprioceptive axons ectopically invade the dorsal horn (Yoshida et al., 2006; Leslie et al., 2011; Figure 4A). Since proprioceptive axons are heavily myelinated, and most cutaneous axons are thinly myelinated if at all, oligodendrocytes associated with proprioceptive axons invade the dorsal spinal cord, and then inhibit synapse formation in the absence of Sema6D-PlexA1 signaling (Yoshida et al., 2006; Leslie et al., 2011; Figure 4A). Genetic deletion of oligodendrocytes demonstrates that it is the ectopic oligodendrocytes, not proprioceptive axons, in the dorsal spinal cord that inhibit synapse formation, but not axonal growth, in Sema6D mutants (Leslie et al., 2011; Figure 4A). Therefore, ectopic oligodendrocytes in the dorsal spinal cord inhibit synapse formation in the absence of Sema6D-PlexA1 signaling.

Once proprioceptive axons reach the ventral spinal cord, most make monosynaptic connections with specific motor neurons; however, a subset of proprioceptive axons at cervical levels form di- or poly-synaptic interneuronal connections (Vrieseling and Arber, 2006; reviewed in Ladle et al., 2007). Interestingly, PlexD1 and its ligand Sema3E regulate avoidance of monosynaptic connections between cutaneous maximus $(\mathrm{Cm})$ sensory and motor neurons (Pecho-Vrieseling et al., 2009; Figure 4B). Unlike most Ia afferents and motor neuron pools that project to the same muscle, $\mathrm{Cm}$ Ia afferents do not make monosynaptic connections with $\mathrm{Cm}$ motor neurons in wild-type mice (Vrieseling and Arber, 2006; Figure 4B). However, genetic deletion of PlexD1 or Sema3E results in aberrant monosynaptic Ia afferent connectivity with this motor neuron pool (Pecho-Vrieseling et al., 2009; Figure 4B). Furthermore, ectopic expression of Sema3E in triceps (Tri) motor neurons prevents monosynaptic sensory-motor connectivity (PechoVrieseling et al., 2009; Figure 4B). Thus, repulsive Sema3E-PlexD1 signaling controls the exclusion of sensory afferent inputs on CM motor neuron pool.

\section{SYNAPSE FORMATION IN THE STRIATUM}

The striatum receives convergent excitatory inputs from the cortex and thalamus. Specific excitatory synaptic connections are formed between axons arising from these two regions and their two functionally distinct populations of targets: the direct and the indirect pathway of striatal medium spiny neurons (MSNs; Surmeier et al., 2007). Very recently, Ding et al. (2012) demonstrated that Sema3EPlexD1 signaling controls pathway-specific synapse formation in the striatum. The authors first find that PlexD1 is expressed by the direct pathway, but not the indirect pathway, MSNs, whereas $S e m a 3 E$ is expressed in the thalamus and in deep cortical layers, the two principal sources of glutamatergic inputs to the striatum (Ding et al., 2012). AMPA receptor-mediated spontaneous miniature excitatory postsynaptic currents (mEPSCs) were measured using the whole-cell voltage-clamp recording, and loss of either Sema3E or PlexD1 was found to lead to a large increase in $\mathrm{mEPSC}$ frequency, but not amplitude, in direct pathway MSNs (Ding et al., 2012). Furthermore, optogenetic activation of thalamostriatal axons showed that loss of PlexD1 or Sema3E leads to large evoked thalamostriatal EPSCs in the direct pathway MSNs, and loss of PlexD1 increases thalamostriatal synapse number (Ding et al., 2012). In thalamostriatal projections, Sema3E is secreted by axons and PlexD1 is expressed by postsynaptic neurons. Therefore, it is unlikely that Sema3E-PlexD1 signaling affects the targeting axons, as is observed in the spinal cord (Pecho-Vrieseling et al., 2009). Instead, Sema3E-PlexD1 signaling may control thalamostriatal synaptic strength by regulating postsynaptic sites through the PlexD1 receptor (Figure 5). For example, PlexD1 receptor signaling may alter the cytoskeleton or regulate glutamate receptor trafficking and stabilization. Alternatively, Sema3E-PlexD1 signaling may produce a secreted molecule to induce a retrograde signal in the postsynaptic sites that repels thalamostriatal axons.

\section{AXON PRUNING}

The CST axon projection pattern is known to be modified during neural development by stereotyped axon pruning (Thong and Dreher, 1987; Stanfield, 1992). Cortical motor neurons extending from the rostral cortex prune axons that extend to the superior 
A

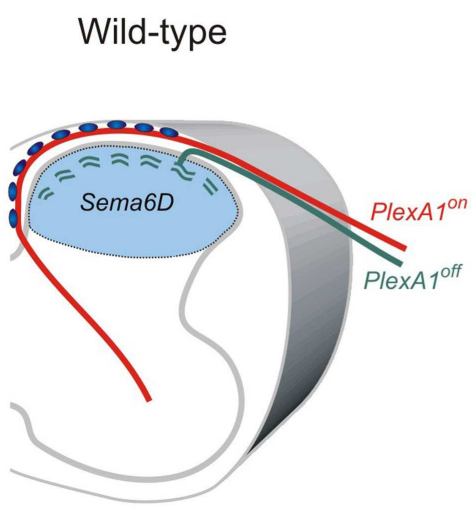

B

Wild-type

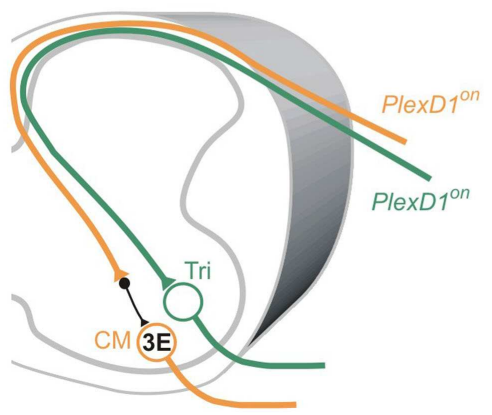

PlexA1\%

or Sema6D-/-

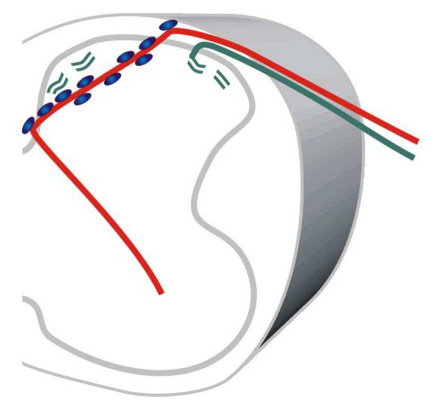

PlexD1-/-

or

Sema3E-/-

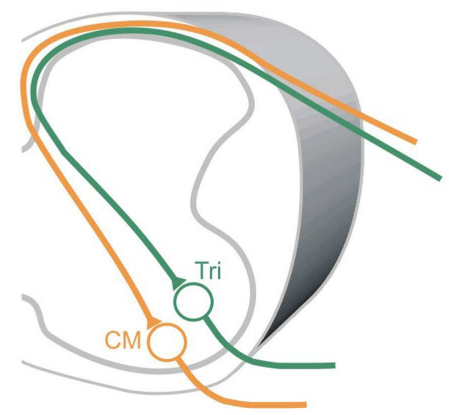

Sema6D-/-; Cnp-Cre; lox-stop-lox-DTA

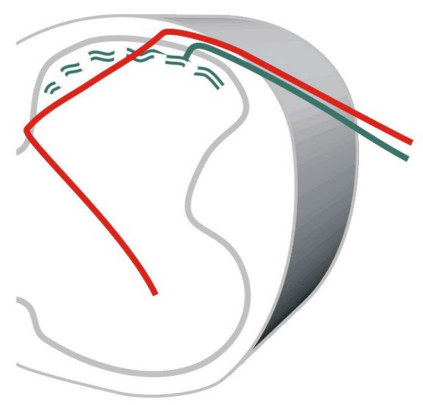

$M N:: S e m a 3 E$
FIGURE 4 | Roles of semaphorin-plexin signaling in sensory-motor circuitry. (A) Cross-sectional diagrams depicting the dorsal spinal cords of wild-type, PlexA1, and Sema6D, and oligodendrocyte-deleted Sema6D mutant mice used in two studies (Yoshida et al., 2006; Leslie et al., 2011). Proprioceptive axons (red lines), oligodendrocytes (blue circles), cutaneous axons (green lines), cutaneous synapses (green wavy lines). Blue areas show Sema6D-expressing region. PlexA1 is expressed by proprioceptive sensory neurons but not cutaneous sensory neurons. Cutaneous synapses are disrupted when oligodendrocytes aberrantly enter the dorsal horn, whereas genetic deletion of oligodendrocytes from Sema6D mutants rescues these synaptic defects. (B) Cross-sectional diagrams depicting the spinal cords of wild-type, PlexD1, and Sema3E mutant mice as well as motor neuron-specific Sema3E-expressing mice (Pecho-Vrieseling et al., 2009). Motor neurons innervating triceps (Tri) muscle receive monosynaptic inputs from Tri sensory afferents, whereas cutaneous maximus (CM) motor neurons lack monosynaptic inputs from CM sensory afferents. Sema3E is expressed by $\mathrm{CM}$ motor neurons but not Tri motor neurons. PlexD1 is expressed by $\sim 80 \%$ of $\mathrm{CM}$ proprioceptive sensory neurons, and $\sim 50 \%$ of Tri proprioceptive sensory neurons. Absence of Sema3E-PlexD1 signaling causes aberrant monosynaptic sensory-motor connections between $\mathrm{CM}$ sensory and $\mathrm{CM}$ motor neurons. Ectopic expression of Sema3E in Tri motor neurons reduces monosynaptic connections between Tri afferents and Tri motor neurons. and inferior colliculi, whereas cortical neuron axons extending from visual cortex prune axons they initially extend to the inferior colliculus and the spinal cord (Thong and Dreher, 1987; Stanfield, 1992). Plexin receptor signaling selectively controls the stereotyped pruning of corticospinal axons from visual cortex, but not motor cortex (Low et al., 2008). Both anterograde and retrograde tracers show that visual cortex neurons fail to prune axons that extend to the spinal cord in PlexA3/A4 double mutants, or Npn2 mutant mice (Low et al., 2008). Interestingly, unpruned visual CST axon collaterals in PlexA3/A4 double or Npn2 mutant mice retain their synaptic contacts in the spinal cord (Low et al., 2008). However, these unpruned CST axons in PlexA3/A4 double mutants are unmyelinated, suggesting they are likely to be physiologically impaired (Low et al., 2008). Taken together, these studies show that distinct Sema/Npn/plexin signaling events regulate the axonal trajectories of motor CST axons and the pruning of visual CST axons. It remains to be determined exactly how CST motor axon pruning is regulated.

Sema3F/Npn2/PlexA3 signaling has been shown to be required for the stereotyped pruning of mossy fiber axon collaterals (Bagri et al., 2003). A further study has shown that mossy fiber axon collaterals form transient synaptic complexes in the early postnatal mouse hippocampus, and at later postnatal ages these synaptic complexes stop maturating and are removed before stereotyped pruning (Liu et al., 2005). A recent study also shows that not only class 3 semaphorins but also a transmembrane class 5 semaphorin can mediate synapse elimination in cultured hippocampal neurons (O'Connor et al., 2009). Therefore, distinct classes of semaphorins may have roles in synapse pruning and elimination in different regions in the nervous system. Future analysis using a 


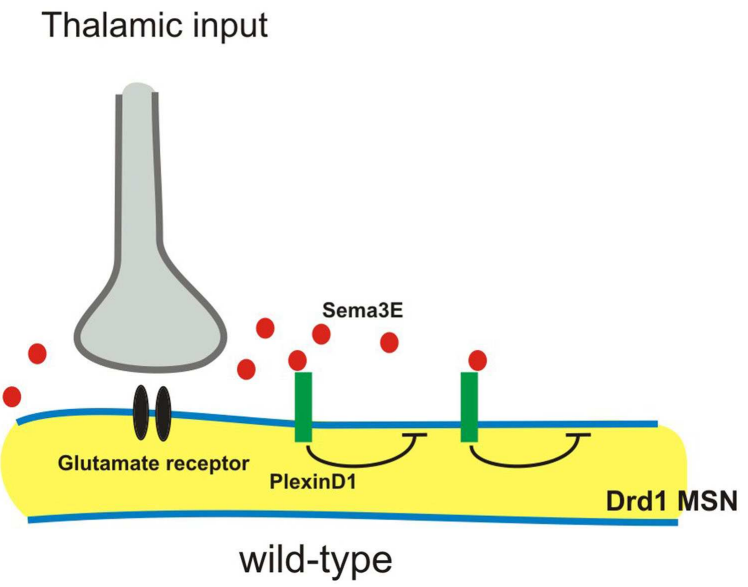

FIGURE 5 | Sema3E-PlexD1 signaling regulates pathway-specific synapse formation in the striatum. Direct and indirect pathway MSNs are functionally and molecularly distinct. Direct pathway MSNs express type 1 dopamine receptors (Drd1) and indirect pathway MSNs express type 2 dopamine receptors (Drd2). PlexD1 is exprsssed by Drd1 ${ }^{\text {on }}$-direct pathway

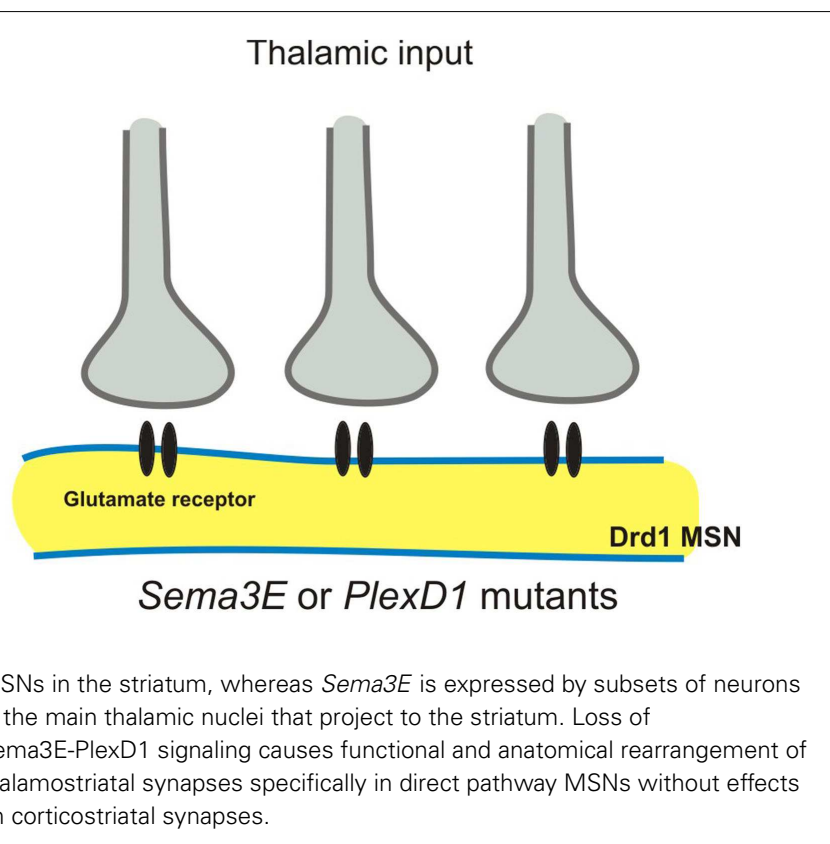

mouse genetics will reveal the in vivo roles of class 5 semaphorins in axon elimination.

\section{MECHANISMS OF SEMAPHORIN ACTION SWITCHING BETWEEN ATTRACTION AND REPULSION}

Some semaphorins have been shown to exhibit both attractive and repulsive activities in vitro and in vivo (Song et al., 1998; Castellani et al., 2000, 2002; Wolman et al., 2004). Recent studies show novel mechanisms underlying the switch of Sema3E function from axonal repulsion to attraction (Chauvet et al., 2007; Bellon et al., 2010). First, Mann's group looked in detail at the expression of Sema3E, Npn1, and PlexD1 in the developing brain, and examined their function (Chauvet et al., 2007). Corticofugal and striatonigral neurons expressing PlexD1, but not Npn1, respond to Sema3E as a repulsive cue (Chauvet et al., 2007). In contrast, subiculo-mammillary neurons express both PlexD1 and Npn1, and on these neurons Sema3E acts as an attractant (Chauvet et al., 2007). Since the extracellular domain alone of Npn1 is sufficient to convert repulsive signaling by PlexD1 to attraction, the involvement of another co-receptor capable of signaling this switch is suggested to mediate Sema3E attractive function (Chauvet et al., 2007). A recent study addresses this issue and shows that VEGFR2 (KDR/Flk1) acts as a co-receptor for a Sema3E/Npn1/PlexD1 attractive signaling complex (Bellon et al., 2010). VEGFR2 is expressed by neurons of the subiculum and mediates axonal elongation in response to Sema3E in vitro, and VEGFR2 interacts with the Npn1/PlexD1 receptor complex (Bellon et al., 2010). Furthermore, VEGFR2 is required for Sema3E-mediated axonal elongation but not axonal repulsion, both in vitro and in vivo (Bellon et al., 2010). These observations demonstrate that PlexD1 transduces the Sema3E-mediated repulsive signal, whereas VEGFR2/Npn1/PlexD1 complex transduces the Sema3E-mediated attractive signal.

Another recent study shows that Sema3F is a bifunctional (repulsive and attractive) cue for dopaminergic axons (Kolk et al.,
2009). Dopaminergic neurons in the mesodiencephalon (mdDA neurons) make precise synaptic connections with their target neurons in the forebrain. In the elaboration of this circuit during early developmental stages, a Sema3F-mediated repulsive signaling controls mdDA pathway development through both Npn2-dependent (axon fasciculation and channeling) and Npn2-independent (rostral growth) mechanisms (Kolk et al., 2009). During later developmental stages, Sema3F-mediated attractive signaling through the Npn2 receptor is required to orient mdDA axonal projections in the cortical plate of the medial prefrontal cortex (Kolk et al., 2009). Thus, the same semaphorins can be both attractive and repulsive. A recent work in flies demonstrates the phylogenetic conservation of semaphorin bifunctionality (Wu et al., 2011). This bifunctionality may be dependent on the expression of distinct coreceptors, could involve different interactions with same receptor that result in intracellular different signaling events, and most certainly requires the engagement of distinct intracellular signaling pathways capable of mediated attraction or repulsion.

The ratio of cAMP/cGMP has also been shown to regulate axonal attraction or repulsion in vitro (Song et al., 1998). Moreover, cyclic nucleotide-gated channels (CNGCs) have been suggested to function in axonal pathfinding in vivo (Coburn and Bargmann, 1996; Komatsu et al., 1996; Zheng et al., 2000). A recent study has shown that cyclic-GMP-gated CNG channels function in Sema3A-induced growth cone repulsion in Xenopus (Togashi et al., 2008). Future studies will determine whether mouse cyclicGMP-gated CNG channels are also involved in Sema3A-mediated axonal repulsion.

\section{REGULATION OF SEMAPHORIN SIGNALING}

Recent several studies have demonstrated how semaphorin signaling might be regulated. First, fibroblast growth factor 8 (FGF8) has been shown to repel midbrain dopaminergic neuron (mDAN) axons that extend through the diencephalon (Yamauchi et al., 2009). This repulsion seems to be mediated by Sema3F, since 
the expression of $\mathrm{Sema3F}$ is up-regulated by ectopic expression of FGF8 and Sema3F repels mDAN axonal growth (Yamauchi et al., 2009). Thus, regulation of Sema3F expression by FGF8 provides a robust mechanism for mediating mDAN axon repulsion in vivo. Another study shows that Robol regulates Npnl and PlexA1 expression and thereby facilitates the migration of cortical interneurons through the ventral forebrain (Hernández-Miranda et al., 2011). Interestingly, this study further shows that Robo1 binds directly to Npn 1 and this interaction is mediated by a region contained within its first two Robo Ig domains. Therefore, Robo1 has the potential to modulate semaphorin signaling by regulating $\mathrm{Npn} 1$ and PlexAl expression, and by interacting with Npn1. Interestingly, a recent study shows that a microRNA, miR-124, regulates Npn1 expression in Xenopus neurons (Baudet et al., 2011). Since miR-124 knockdown induces the downregulation of Npn1 in the growth cone, miR-124 knockdown also delays onset of Sema3A sensitivity (Baudet et al., 2011). As miRNAs in general repress the expression of their target mRNAs and $\mathrm{Npn} 1$ is unlikely to be their target, miR-124 appears to regulate Npn1 expression indirectly. Then CoREST, a transcriptional co-repressor that influences Npn1 expression, was identified as a target and mediator of miR-124 (Baudet et al., 2011). Finally, a miR-124 morphant results in RGC axon targeting errors in vivo (Baudet et al., 2011). Taken together, these findings suggest that miR-124 is important for regulating the

\section{REFERENCES}

Artigiani, S., Conrotto, P., Fazzari, P., Gilestro, G. F., Barberis, D., Giordano, S., Comoglio, P. M., and Tamagnone, L. (2004). Plexin-B3 is a functional receptor for semaphorin 5A. EMBO Rep. 5, 710-714.

Bagnard, D., Lohrum, M., Uziel, D., Puschel, A. W., and Bolz, J. (1998). Semaphorins act as attractive and repulsive guidance signals during the development of cortical projections. Development 125, 5043-5053.

Bagri, A., Cheng, H. J., Yaron, A., Pleasure, S. J., and Tessier-Lavigne, M. (2003). Stereotyped pruning of long hippocampal axon branches triggered by retraction inducers of the semaphorin family. Cell 113, 285-299.

Baudet, M. L., Zivraj, K. H., AbreuGoodger, C., Muldal, A., Armisen, J., Blenkiron, C., Goldstein, L. D., Miska, E. A., and Holt, C. E. (2011). miR-124 acts through CoREST to control onset of Sema3A sensitivity in navigating retinal growth cones. Nat. Neurosci. 15, 29-38.

Behar, O., Golden, J. A., Mashimo, H., Schoen, F. J., and Fishman, M. C. (1996). Semaphorin III is needed for normal patterning and growth of nerves, bones and heart. Nature 383, 525-528.

Bellon, A., Luchino, J., Haigh, K., Rougon, G., Haigh, J., Chauvet, S., and Mann, F. (2010). VEGFR2 (KDR/Flk1) signaling mediates axon

intrinsic temporal changes in RGC growth cone responsiveness by controlling onset of sensitivity to Sema3A.

\section{CONCLUSION}

Semaphorins and their receptors, plexins, Npns, and various coreceptors, play many roles in each step of neural circuit assembly. These include neural migration, neuronal polarity, axon guidance, dendrite development, synapse formation, and synaptic function in the PNS and CNS. Future studies will likely reveal more details of how semaphorin signaling is involved in neural circuit assembly, especially the roles of semaphorin signaling in postnatal and adult neural circuitry, neuronal degeneration/regeneration, and the interactors upstream and downstream of semaphorin signaling. If we have better understanding of roles of semaphorin signaling in neural circuit formation, the information will be likely to provide a template for understanding how other signaling pathways work in the nervous system. Together the information will be able to lead to a sense of unified mechanisms that govern the establishment of neural circuit formation.

\section{ACKNOWLEDGMENTS}

I am grateful to R. Giger, A. Kolodkin, T. Kuwajima, C. Mason, and R. Mastuoka, for helpful comments on this manuscript. Y. Yoshida is supported by grants from NINDS (NS065048).

axonal repulsion to attraction during brain development. Neuron 56, 807-822.

Chen, G., Sima, J., Jin, M., Wang, K. Y. Xue, X. J., Zheng, W., Ding, Y. Q., and Yuan, X. B. (2008). Semaphorin-3A guides radial migration of cortical neurons during development. Nat. Neurosci. 11, 36-44.

Cheng, H. J., Bagri, A., Yaron, A., Stein, E., Pleasure, S. J., and TessierLavigne, M. (2001). Plexin-A3 mediates semaphorin signaling and regulates the development of hippocampal axonal projections. Neuron 32 249-263.

Coburn, C. M., and Bargmann, C. I. (1996). A putative cyclic nucleotidegated channel is required for sensory development and function in $C$. elegans. Neuron 17, 695-706.

Cohen, S., Funkelstein, L., Livet, J., Rougon, G., Henderson, C. E., Castellani, V., and Mann, F. (2005). A semaphorin code defines subpopulations of spinal motor neurons during mouse development. Eur. J. Neurosci. 21, 1767-1776.

de Winter, F., Cui, Q., Symons, N., Verhaagen, J., and Harvey, A. R. (2004). Expression of class-3 semaphorins and their receptors in the neonatal and adult rat retina. Invest. Ophthalmol. Vis. Sci. 45, 4554-4562.

Ding, J. B., Oh, W. J., Sabatini, B. L. and Gu, C. (2012). Semaphorin 3E-Plexin-D1 signaling controls pathway-specific synapse formation in the striatum. Nat. Neurosci. 15, 215-223.

Erskine, L., Reijntjes, S., Pratt, T., Denti, L., Schwarz, Q., Vieira, J. M., Alakakone, B., Shewan, D., and Ruhrberg, C. (2011). VEGF signaling through neuropilin 1 guides commissural axon crossing at the optic chiasm. Neuron 70, 951-965.

Falk, J., Bechara, A., Fiore, R., Nawabi, H., Zhou, H., Hoyo-Becerra, C., Bozon, M., Rougon, G., Grumet, M., Püschel, A. W., Sanes, J. R., and Castellani, V. (2005). Dual functional activity of semaphorin $3 \mathrm{~B}$ is required for positioning the anterior commissure. Neuron 48, 63-75.

Faulkner, R. L., Low, L. K., Liu, X. B., Coble, J., Jones, E. G., and Cheng, H. J. (2008). Dorsal turning of motor corticospinal axons at the pyramidal decussation requires plexin signaling. Neural Dev. 3, 21.

Fenstermaker, V., Chen, Y., Ghosh, A., and Yuste, R. (2004). Regulation of dendritic length and branching by semaphorin 3A. J. Neurobiol. 58, 403-412.

Friedel, R. H., Kerjan, G., Rayburn, H., Schüller, U., Sotelo, C., TessierLavigne, M., and Chédotal, A. (2007). Plexin-B2 controls the development of cerebellar granule cells. $J$. Neurosci. 27, 3921-3932.

Fu, S. Y., Sharma, K., Luo, Y., Raper, J. A., and Frank, E. (2000). SEMA3A regulates developing sensory 
projections in the chicken spinal cord. J. Neurobiol. 45, 227-236.

Gu, C., Rodriguez, E. R., Reimert, D. V., Shu, T., Fritzsch, B., Richards, L. J., Kolodkin, A. L., and Ginty, D. D. (2003). Neuropilin-1 conveys semaphorin and VEGF signaling during neural and cardiovascular development. Dev. Cell 5, 45-57.

Gu, C., Yoshida, Y., Livet, J., Reimert, D. V., Mann, F., Merte, J., Henderson, C. E., Jessell, T. M., Kolodkin, A. L., and Ginty, D. D. (2005). Semaphorin 3E and plexin-D1 control vascular pattern independently of neuropilins. Science 307, 265-268.

Hernández-Miranda, L. R., Cariboni, A., Faux, C., Ruhrberg, C., Cho, J. H., Cloutier, J. F., Eickholt, B. J., Parnavelas, J. G., and Andrews, W. D. (2011). Robol regulates semaphorin signaling to guide the migration of cortical interneurons through the ventral forebrain. J. Neurosci. 31, 6174-6187.

Huber, A. B., Kania, A., Tran, T. S., Gu, C., De Marco Garcia, N., Lieberam, I., Johnson, D., Jessell, T. M., Ginty, D. D., and Kolodkin, A. L. (2005). Distinct roles for secreted semaphorin signaling in spinal motor axon guidance. Neuron 48, 949-964.

Huettl, R. E., Soellner, H., Bianchi, E., Novitch, B. G., and Huber, A. B. (2011). Npn-1 contributes to axon-axon interactions that differentially control sensory and motor innervation of the limb. PLoS Biol. 9, e1001020. doi:10.1371/journal.pbio.1001020

Imai, T., Suzuki, M., and Sakano, H. (2006). Odorant receptor-derived cAMP signals direct axonal targeting. Science 314, 657-661.

Imai, T., Yamazaki, T., Kobayakawa, R., Kobayakawa, K., Abe, T., Suzuki, M., and Sakano, H. (2009). Pretarget axon sorting establishes the neural map topography. Science 325 , 585-590.

Jan, Y. N., and Jan, L. Y. (2003). The control of dendrite development. Neuron 40, 229-242.

Kerjan, G., Dolan, J., Haumaitre, C., Schneider-Maunoury, S., Fujisawa, H., Mitchell, K. J., and Chédotal, A. (2005). The transmembrane semaphorin Sema6A controls cerebellar granule cell migration. Nat. Neurosci. 8, 1516-1524.

Kikutani, H., and Kumanogoh, A. (2003). Semaphorins in interactions between $\mathrm{T}$ cells and antigenpresenting cells. Nat. Rev. Immunol. 3, 159-167.

Kitsukawa, T., Shimizu, M., Sanbo, M., Hirata, T., Taniguchi, M., Bekku, Y., Yagi, T., and Fujisawa,
H. (1997). Neuropilin-semaphorin III/D-mediated chemorepulsive signals play a crucial role in peripheral nerve projection in mice. Neuron 19 , 995-1005.

Koerber, H. R., and Mendell, L. M. (1992). "Functional heterogeneity of dorsal root ganglion cells," in Sensory Neurons: Diversity, Development and Plasticity, ed. S. A. Scott (New York: Oxford University Press), 77-96.

Kolk, S. M., Gunput, R. A., Tran, T. S., van den Heuvel, D. M., Prasad, A. A., Hellemons, A. J., Adolfs, Y., Ginty, D. D., Kolodkin, A. L., Burbach, J. P., Smidt, M. P., and Pasterkamp, R. J. (2009). Semaphorin 3F is a bifunctional guidance cue for dopaminergic axons and controls their fasciculation, channeling, rostral growth, and intracortical targeting. J. Neurosci. 29, 12542-12557.

Komatsu, H., Mori, I., Rhee, J. S., Akaike, N., and Ohshima, Y. (1996). Mutations in a cyclic nucleotidegated channel lead to abnormal thermosensation and chemosensation in C. elegans. Neuron 17, 707-718.

Komuro, H., Yacubova, E., Yacubova, E., and Rakic, P. (2001). Mode and tempo of tangential cell migration in the cerebellar external granular layer. J. Neurosci. 21, 527-540.

Kumanogoh, A., Marukawa, S., Suzuki, K., Takegahara, N., Watanabe, C., Ch'Ng, E., Ishida, I., Fujimura, H., Sakoda, S., Yoshida, K., and Kikutani, H. (2002). Class IV semaphorin Sema4A enhances T-cell activation and interacts with Tim-2. Nature 419, 629-633.

Kumanogoh, A., Watanabe, C., Lee, I., Wang, X., Shi, W., Araki, H., Hirata, H., Iwahori, K., Uchida, J., Yasui, T., Matsumoto, M., Yoshida, K., Yakura, H., Pan, C., Parnes, J. R., and Kikutani, H. (2000). Identification of CD72 as a lymphocyte receptor for the class IV semaphorin CD100: a novel mechanism for regulating B cell signaling. Immunity 13 , 621-631.

Kuwajima, T., Yoshida, Y., Takegahara, N., Kumanogoh, A., Petros, T. J., Jessell, T. M., Sakurai, T., and Mason, C. (2012). Optic chiasm presentation of Semaphorin6D in the context of Plexin-Al and Nr-CAM promotes retinal axon midline crossing. Neuron 74, 676-690.

Ladle, D. R., Pecho-Vrieseling, E., and Arber, S. (2007). Assembly of motor circuits in the spinal cord: driven to function by genetic and experiencedependent mechanisms. Neuron 56, 270-283.

Landmesser, L. (1978). The development of motor projection patterns in the chick hind limb. J. Physiol. (Lond.) 284, 391-414.

Leighton, P. A., Mitchell, K. J., Goodrich, L. V., Lu, X., Pinson, K., Scherz, P., Skarnes, W. C., and Tessier-Lavigne, M. (2001). Defining brain wiring patterns and mechanisms through gene trapping in mice. Nature 410 , 174-179.

Leslie, J. R., Imai, F., Fukuhara, K., Takegahara, N., Rizvi, T. A., Friedel, R. H., Wang, F., Kumanogoh, A., and Yoshida, Y. (2011). Ectopic myelinating oligodendrocytes in the dorsal spinal cord as a consequence of altered semaphorin $6 \mathrm{D}$ signaling inhibit synapse formation. Development 138, 4085-4095.

Little, G. E., López-Bendito, G., Rünker, A. E., García, N., Piñon, M. C., Chédotal, A., Molnár, Z., and Mitchell, K. J. (2009). Specificity and plasticity of thalamocortical connections in Sema6A mutant mice. PLoS Biol. 7, e98. doi:10.1371/journal.pbio.1000098

Liu, X. B., Low, L. K., Jones, E. G., and Cheng, H. J. (2005). Stereotyped axon pruning via plexin signaling is associated with synaptic complex elimination in the hippocampus. $J$. Neurosci. 25, 9124-9134.

Low, L. K., Liu, X. B., Faulkner, R. L., Coble, J., and Cheng, H. J. (2008). Plexin signaling selectively regulates the stereotyped pruning of corticospinal axons from visual cortex. Proc. Natl. Acad. Sci. U.S.A. 105, 8136-8141.

Maier, V., Jolicoeur, C., Rayburn, H., Takegahara, N., Kumanogoh, A., Kikutani, H., Tessier-Lavigne, M., Wurst, W., and Friedel, R. H. (2011). Semaphorin $4 \mathrm{C}$ and $4 \mathrm{G}$ are ligands of Plexin-B2 required in cerebellar development. Mol. Cell. Neurosci.46, 419-431.

Mann, F., Chauvet, S., and Rougon, G. (2007). Semaphorins in development and adult brain: implication for neurological diseases. Prog. Neurobiol. 82, 57-79.

Marín, O., Yaron, A., Bagri, A., Tessier-Lavigne, M., and Rubenstein, J. L. (2001). Sorting of striatal and cortical interneurons regulated by semaphorin-neuropilin interactions. Science 293, 872-875.

Matsuoka, R. L., Chivatakarn, O., Badea, T. C., Samuels, I. S., Cahill, H., Katayama, K., Kumar, S. R., Suto, F., Chédotal, A., Peachey, N. S., Nathans, J., Yoshida, Y., Giger, R. J., and Kolodkin, A. L. (2011a). Class 5 transmembrane semaphorins control selective Mammalian retinal lamination and function. Neuron 71 , 460-473.
Matsuoka, R. L., Nguyen-Ba-Charvet, K. T., Parray, A., Badea, T. C., Chédotal, A., and Kolodkin, A. L. (2011b). Transmembrane semaphorin signalling controls laminar stratification in the mammalian retina. Nature 470, 259-263.

Mauti, O., Domanitskaya, E., Andermatt, I., Sadhu, R., and Stoeckli, E. T. (2007). Semaphorin6A acts as a gate keeper between the central and the peripheral nervous system. Neural Dev. 2, 28.

Messersmith, E. K., Leonardo, E. D., Shatz, C. J., Tessier-Lavigne, M., Goodman, C. S., and Kolodkin, A. L. (1995). Semaphorin III can function as a selective chemorepellent to pattern sensory projections in the spinal cord. Neuron 14, 949-959.

Mombaerts, P. (2006). Axonal wiring in the mouse olfactory system. Annu. Rev. Cell Dev. Biol. 22, 713-737.

Moret, F., Renaudot, C., Bozon, M., and Castellani, V. (2007). Semaphorin and neuropilin co-expression in motoneurons sets axon sensitivity to environmental semaphorinsources during motor axon pathfinding. Development 134, 4491-4501.

Mori, K., and Sakano, H. (2011). How is the olfactory map formed and interpreted in the mammalian brain? Annu. Rev. Neurosci. 34, 467-499.

Mumm, J. S., Williams, P. R., Godinho, L., Koerber, A., Pittman, A. J., Roeser, T., Chien, C. B., Baier, H., and Wong, R. O. (2006). In vivo imaging reveals dendritic targeting of laminated afferents by zebrafish retinal ganglion cells. Neuron 52, 609-621.

Nawabi, H., Briançon-Marjollet, A., Clark, C., Sanyas, I., Takamatsu, H., Okuno, T., Kumanogoh, A., Bozon, M., Takeshima, K., Yoshida, Y., Moret, F., Abouzid, K., and Castellani, V. (2010). A midline switch of receptor processing regulates commissural axon guidance in vertebrates. Genes Dev. 24, 396-410.

Niquille, M., Garel, S., Mann, F., Hornung, J. P., Otsmane, B., Chevalley, S., Parras, C., Guillemot, F., Gaspar, P., Yanagawa, Y., and Lebrand, C. (2009). Transient neuronal populations are required to guide callosal axons: a role for semaphorin 3C. PLoS Biol. 7, el000230. doi:10.1371/journal.pbio.1000230

Nishiyama, M., Togashi, K., von Schimmelmann, M. J., Lim, C. S., Maeda, S., Yamashita, N., Goshima, Y., Ishii, S., and Hong, K. (2011). Semaphorin $3 \mathrm{~A}$ induces CaV2.3 channeldependent conversion of axons to dendrites. Nat. Cell Biol. 13, 676-685. 
O'Connor, T. P., Cockburn, K., Wang, W., Tapia, L., Currie, E., and Bamji, S. X. (2009). Semaphorin 5B mediates synapse elimination in hippocampal neurons. Neural Dev. 4, 18.

Okado, N., Homma, S., Ishihara, R., and Kohno, K. (1990). Distribution patterns of dendrites in motor neuron pools of lumbosacral spinal cord of the chicken. Anat. Embryol. 182, 113-121.

Paradis, S., Harrar, D. B., Lin, Y., Koon, A. C., Hauser, J. L., Griffith, E. C., Zhu, L., Brass, L. F., Chen, C., and Greenberg, M. E. (2007). An RNAi-based approach identifies molecules required for glutamatergic and GABAergic synapse development. Neuron 53, 217-232.

Parra, L. M., and Zou, Y. (2010). Sonic hedgehog induces response of commissural axons to Semaphorin repulsion during midline crossing. Nat. Neurosci. 13, 29-35.

Pasterkamp, R. J., and Giger, R. J. (2009). Semaphorin function in neural plasticity and disease. Curr. Opin. Neurobiol. 19, 263-274.

Pasterkamp, R. J., Peschon, J. J., Spriggs, M. K., and Kolodkin, A. L. (2003). Semaphorin 7A promotes axon outgrowth through integrins and MAPKs. Nature 424, 398-405.

Pecho-Vrieseling, E., Sigrist, M., Yoshida, Y., Jessell, T. M., and Arber, S. (2009). Specificity of sensorymotor connections encoded by Sema3e-Plxnd1 recognition. Nature $459,842-826$.

Polleux, F., Morrow, T., and Ghosh, A. (2000). Semaphorin $3 \mathrm{~A}$ is a chemoattractant for cortical apical dendrites. Nature 404, 567-573.

Porter, L. L., and White, E. L. (1983). Afferent and efferent pathways of the vibrissal region of primary motor cortex in the mouse. J. Comp. Neurol. 214, 279-289.

Renaud, J., Kerjan, G., Sumita, I., Zagar, Y., Georget, V., Kim, D., Fouquet, C., Suda, K., Sanbo, M., Suto, F., Ackerman, S. L., Mitchell, K. J., Fujisawa, H., and Chédotal, A. (2008). Plexin$\mathrm{A} 2$ and its ligand, Sema6A, control nucleus-centrosome coupling in migrating granule cells. Nat. Neurosci. 11, 440-409.

Ruhrberg, C., Gerhardt, H., Golding, M., Watson, R., Ioannidou, S., Fujisawa, H., Betsholtz, C., and Shima, D. T. (2002). Spatially restricted patterning cues provided by heparinbinding VEGF-A control blood vessel branching morphogenesis. Genes Dev. 16, 2684-2698.

Rünker, A. E., Little, G. E., Suto, F., Fujisawa, H., and Mitchell, K. J. (2008). Semaphorin-6A controls guidance of corticospinal tract axons at multiple choice points. Neural Dev. 3, 34.

Ryder, E. F., and Cepko, C. L. (1994). Migration patterns of clonally related granule cells and their progenitors in the developing chick cerebellum. Neuron 12, 1011-1028.

Sahay, A., Kim, C. H., Sepkuty, J. P., Cho, E., Huganir, R. L., Ginty, D. D., and Kolodkin, A. L. (2005). Secreted semaphorins modulate synaptic transmission in the adult hippocampus. J. Neurosci. 25, 3613-3620.

Sanes, J. R., and Zipursky, S. L. (2010). Design principles of insect and vertebrate visual systems. Neuron 66, $15-36$.

Schwarz, Q., Gu, C., Fujisawa, H., Sabelko, K., Gertsenstein, M., Nagy, A., Taniguchi, M., Kolodkin, A. L., Ginty, D. D., Shima, D. T., and Ruhrberg, C. (2004). Vascular endothelial growth factor controls neuronal migration and cooperates with Sema3A to pattern distinct compartments of the facial nerve. Genes Dev. 18, 2822-2834.

Shelly, M., Cancedda, L., Heilshorn, S., Sumbre, G., and Poo, M. M. (2007). LKB1/STRAD promotes axon initiation during neuronal polarization. Cell 129, 565-577.

Shelly, M., Cancedda, L., Lim, B. K., Popescu, A. T., Cheng, P. L., Gao, H., and Poo, M. M. (2011). Semaphorin3A regulates neuronal polarization by suppressing axon formation and promoting dendrite growth. Neuron 71, 433-446.

Shelly, M., Lim, B. K., Cancedda, L., Heilshorn, S. C., Gao, H., and Poo, M. M. (2010). Local and long-range reciprocal regulation of cAMP and cGMP in axon/dendrite formation. Science 327, 547-552.

Song, H., Ming, G., He, Z., Lehmann, M., McKerracher, L., TessierLavigne, M., and Poo, M. (1998). Conversion of neuronal growth cone responses from repulsion to attraction by cyclic nucleotides. Science 281, 1515-1518.

Stacy, R. C., and Wong, R. O. (2003). Developmental relationship between cholinergic amacrine cell processes and ganglion cell dendrites of the mouse retina. J. Comp. Neurol. 456, 154-166.

Stanfield, B. B. (1992). The development of the corticospinal projection. Prog. Neurobiol. 38, 169-202.

Surmeier, D. J., Ding, J., Day, M., Wang, Z., and Shen, W. (2007). D1 and D2 dopamine-receptor modulation of striatal glutamatergic signaling in striatal medium spiny neurons. Trends Neurosci. 30, 228-235.

Suto, F., Ito, K., Uemura, M., Shimizu, M., Shinkawa, Y., Sanbo, M., Shinoda, T., Tsuboi, M., Takashima, S. Yagi, T., and Fujisawa, H. (2005). Plexin-a4 mediates axon-repulsive activities of both secreted and transmembrane semaphorins and plays roles in nerve fiber guidance. J. Neurosci. $25,3628-3637$.

Suto, F., Tsuboi, M., Kamiya, H., Mizuno, H., Kiyama, Y., Komai, S. Shimizu, M., Sanbo, M., Yagi, T. Hiromi, Y., Chédotal, A., Mitchell, K. J., Manabe, T., and Fujisawa, H. (2007). Interactions between plexin$\mathrm{A} 2$, plexin- $\mathrm{A} 4$, and semaphorin $6 \mathrm{~A}$ control lamina-restricted projection of hippocampal mossy fibers. Neuron 53, 535-547.

Suzuki, K., Kumanogoh, A., and Kikutani, H. (2008). Semaphorins and their receptors in immune cell interactions. Nat. Immunol. 9, 17-23.

Takahashi, T., Fournier, A., Nakamura, F., Wang, L. H., Murakami, Y., Kalb, R. G., Fujisawa, H., and Strittmatter, S. M. (1999). Plexinneuropilin-1 complexes form functional semaphorin-3A receptors. Cell 99, 59-69.

Takamatsu, H., and Kumanogoh, A. (2012). Diverse roles for semaphorin-plexin signaling in the immune system. Trends Immunol. $33,127-135$.

Takeuchi, H., Inokuchi, K., Aoki, M., Suto, F., Tsuboi, A., Matsuda, I., Suzuki, M., Aiba, A., Serizawa, S. Yoshihara, Y., Fujisawa, H., and Sakano, H. (2010). Sequential arrival and graded secretion of Sema3F by olfactory neuron axons specify map topography at the bulb. Cell 141, 1056-1067.

Tamagnone, L., Artigiani, S., Chen, H., He, Z., Ming, G. I., Song, H., Chedotal, A., Winberg, M. L., Goodman, C. S., Poo, M., TessierLavigne, M., and Comoglio, P. M. (1999). Plexins are a large family of receptors for transmembrane, secreted, and GPI-anchored semaphorins in vertebrates. Cell 99, 71-80.

Taniguchi, M., Yuasa, S., Fujisawa, H., Naruse, I., Saga, S., Mishina, M. and Yagi, T. (1997). Disruption of semaphorin III/D gene causes severe abnormality in peripheral nerve projection. Neuron 19, 519-530.

Tawarayama, H., Yoshida, Y., Suto, F., Mitchell, K. J., and Fujisawa, H. (2010). Roles of semaphorin-6B and plexin-A2 in lamina-restricted projection of hippocampal mossy fibers. J. Neurosci. 30, 7049-7060.
Thong, I. G., and Dreher, B. (1987). The development of the corticotectal pathway in the albino rat: transient projections from the visual and motor cortices. Neurosci. Lett. 80, 275-282.

Togashi, K., von Schimmelmann, M. J., Nishiyama, M., Lim, C. S., Yoshida, N., Yun, B., Molday, R. S., Goshima, Y., and Hong, K. (2008). Cyclic GMP-gated CNG channels function in Sema3A-induced growth cone repulsion. Neuron 58, 694-707.

Toyofuku, T., Yoshida, J., Sugimoto, T., Zhang, H., Kumanogoh, A., Hori, M., and Kikutani, H. (2005). FARP2 triggers signals for Sema3Amediated axonal repulsion. Nat. Neurosci. 8, 1712-1719.

Toyofuku, T., Zhang, H., Kumanogoh, A., Takegahara, N., Suto, F., Kamei, J., Aoki, K., Yabuki, M., Hori, M., Fujisawa, H., and Kikutani, H. (2004). Dual roles of Sema6D in cardiac morphogenesis through regionspecific association of its receptor, Plexin-A1, with off-track and vascular endothelial growth factor receptor type 2. Genes Dev. 18, 435-447.

Tran, T. S., Kolodkin, A. L., and Bharadwaj, R. (2007). Semaphorin regulation of cellular morphology. Annu. Rev. Cell Dev. Biol. 23, 263-292.

Tran, T. S., Rubio, M. E., Clem, R. L., Johnson, D., Case, L., TessierLavigne, M., Huganir, R. L., Ginty, D. D., and Kolodkin, A. L. (2009). Secreted semaphorins control spine distribution and morphogenesis in the postnatal CNS. Nature 462, 1065-1069.

Vermeren, M., Maro, G. S., Bron R., McGonnell, I. M., Charnay, P., Topilko, P., and Cohen, J. (2003). Integrity of developing spinal motor columns is regulated by neural crest derivatives at motor exit points. Neuron 37, 403-415.

Vrieseling, E., and Arber, S. (2006). Target-induced transcriptional control of dendritic patterning and connectivity in motor neurons by the ETS gene Pea3. Cell 127, 1439-1452.

Wässle, H. (2004). Parallel processing in the mammalian retina. Nat. Rev. Neurosci. 5, 747-757.

Williams, S. E., Grumet, M., Colman, D. R., Henkemeyer, M., Mason, C. A., and Sakurai, T. (2006). A role for Nr-CAM in the patterning of binocular visual pathways. Neuron 50, 535-547.

Wingate, R. J. (2001). The rhombic lip and early cerebellar development. Curr. Opin. Neurobiol. 11, 82-88.

Wolman, M. A., Liu, Y., Tawarayama, H., Shoji, W., and Halloran, M. C. 
(2004). Repulsion and attraction of axons by semaphorin3D are mediated by different neuropilins in vivo. J. Neurosci. 24, 8428-8435.

Wu, Z., Sweeney, L. B., Ayoob, J. C., Chak, K., Andreone, B. J., Ohyama, T., Kerr, R., Luo, L., Zlatic, M., and Kolodkin, A. L. (2011). A combinatorial semaphorin code instructs the initial steps of sensory circuit assembly in the Drosophila CNS. Neuron 70, 281-298.

Yamauchi, K., Mizushima, S., Tamada, A., Yamamoto, N., Takashima, S., and Murakami, F. (2009). FGF8 signaling regulates growth of midbrain dopaminergic axons by inducing semaphorin 3F. J. Neurosci. 29, 4044-4055.
Yorke, C. H. Jr., and Caviness, V. S. Jr. (1975). Interhemispheric neocortical connections of the corpus callosum in the normal mouse: a study based on anterograde and retrograde methods. J. Comp. Neurol. 164, 233-245.

Yoshida, Y., Han, B., Mendelsohn, M., and Jessell, T. M. (2006). PlexinA1 signaling directs the segregation of proprioceptive sensory axons in the developing spinal cord. Neuron 52, 775-788.

Zheng, C., Feinstein, P., Bozza, T., Rodriguez, I., and Mombaerts, P. (2000). Peripheral olfactory projections are differentially affected in mice deficient in a cyclic nucleotide-gated channel subunit. Neuron 26, 81-91.

Zhuang, B., Su, Y. S., and Sockanathan, S. (2009). FARP1 promotes the dendritic growth of spinal motor neuron subtypes through transmembrane Semaphorin6A and PlexinA4 signaling. Neuron 61 , 359-372.

Zou, Y., Stoeckli, E., Chen, H., and Tessier-Lavigne, M. (2000). Squeezing axons out of the gray matter: a role for slit and semaphorin proteins from midline and ventral spinal cord. Cell 102, 363-375.

Conflict of Interest Statement: The author declares that the research was conducted in the absence of any commercial or financial relationships that could be construed as a potential conflict of interest.

Received: 29 February 2012; accepted: 17 May 2012; published online: 06 June 2012.

Citation: Yoshida Y (2012) Semaphorin signaling in vertebrate neural circuit assembly. Front. Mol. Neurosci. 5:71. doi: 10.3389/fnmol.2012.00071

Copyright (c) 2012 Yoshida. This is an open-access article distributed under the terms of the Creative Commons Attribution Non Commercial License, which permits non-commercial use, distribution, and reproduction in other forums, provided the original authors and source are credited. 